\title{
ANGUSTIFOLIA, a Plant Homolog of CtBP/BARS Localizes to Stress Granules and Regulates Their Formation
}

\author{
Hemal Bhasin and Martin Hülskamp* \\ Botanik III, Biocenter, University of Cologne, Cologne, Germany
}

OPEN ACCESS

Edited by:

Hirokazu Tsukaya,

University of Tokyo, Japan

Reviewed by:

Gorou Horiguchi,

Rikkyo University, Japan

Takahiro Hamada,

University of Tokyo, Japan

${ }^{*}$ Correspondence:

Martin Hülskamp

martin.huelskamp@uni-koeln.de

Specialty section:

This article was submitted to Plant Evolution and Development,

a section of the journal

Frontiers in Plant Science

Received: 05 April 2017

Accepted: 26 May 2017

Published: 13 June 2017

Citation:

Bhasin H and Hülskamp M (2017) ANGUSTIFOLIA, a Plant Homolog of CtBP/BARS Localizes to Stress

Granules and Regulates Their

Formation. Front. Plant Sci. 8:1004.

doi: 10.3389/fpls.2017.01004
The ANGUSTIFOLIA (AN) gene in Arabidopsis is important for a plethora of morphological phenotypes. Recently, AN was also reported to be involved in responses to biotic and abiotic stresses. It encodes a homolog of the animal C-terminal binding proteins (CtBPs). In contrast to animal CtBPs, AN does not appear to function as a transcriptional co-repressor and instead functions outside nucleus where it might be involved in Golgi-associated membrane trafficking. In this study, we report a novel and unexplored role of AN as a component of stress granules (SGs). Interaction studies identified several RNA binding proteins that are associated with AN. AN co-localizes with several messenger ribonucleoprotein granule markers to SGs in a stress dependent manner. an mutants exhibit an altered SG formation. We provide evidence that the $\mathrm{NAD}(\mathrm{H})$ binding domain of $\mathrm{AN}$ is relevant in this context as proteins carrying mutations in this domain localize to a much higher degree to SGs and strongly reduce AN dimerization and its interaction with one interactor but not the others. Finally, we show that $\mathrm{AN}$ is a negative regulator of salt and osmotic stress responses in Arabidopsis suggesting a functional relevance in SGs.

Keywords: ANGUSTIFOLIA, leaf morphogenesis, trichomes, RNA, NADH

\section{INTRODUCTION}

Overall plant growth and development is based on the regulation of cell shape and cell division/expansion. Cell growth is tightly controlled by cell metabolism and thus by the availability of nutrients, cellular energy, and stress (Yuan et al., 2013). To understand the interplay between cell growth and metabolism, we are studying the ANGUSTIFOLIA (AN) gene in Arabidopsis thaliana. Mutations in $A N$ lead to a plethora of growth phenotypes along with altered responses to stress and pathogen attack. Morphological phenotypes include narrow leaves, under-branched trichomes, spiral growth of roots, ovules, and siliques (Redei, 1962; Hulskamp et al., 1994; Tsukaya et al., 1994; Tsuge et al., 1996; Fulton et al., 2009; Bai et al., 2013). The narrow leaf phenotype is caused by a change in growth directionality of leaf cells and by a decreased number of cells in the width direction (Kim et al., 2002; Bai et al., 2010). The cell shape changes are correlated with changes in the microtubule cytoskeleton (Folkers et al., 2002; Kim et al., 2002; Sambade et al., 2014). More recently, it was reported that an mutants can cope better with drought stress and are more resistant to bacterial infection (Gachomo et al., 2013).

The $A N$ gene encodes for a C-terminal-binding protein/brefeldin A-ADP ribosylated substrate (CtBP/BARS) homolog (Folkers et al., 2002; Kim et al., 2002). BARS are localized in the cytosol 
and have a role in membrane trafficking and Golgi fission (Spano et al., 1999; Colanzi et al., 2013). CtBP was first described as a human protein that interacts with C-terminal sequences Pro-X-Asp-Leu-Ser (PXDLS) of adenovirus E1A protein (Schaeper et al., 1995). One major function of CtBP family proteins is the transcriptional co-repression by binding transcriptional repressors (Chinnadurai, 2002, 2007). CtBP proteins belong to a family of NAD-dependent D2-hydroxy acid dehydrogenases (D2-HDHs) and contain a nicotinamide adenine dinucleotide (NAD) binding domain and a catalytic triad (His/Glu/Arg) that is conserved in all D2-HDHs. The NAD ${ }^{+}$and $\mathrm{NADH}$ ratio in the cell controls the oligomerization of $\mathrm{CtBP}$ and its interaction with E1A. CtBPs have therefore been proposed to act as redox sensors (Zhang et al., 2002; Fjeld et al., 2003).

The molecular role of AN is still not clear. At its $\mathrm{N}$-terminus, AN shares 32\% homology with CtBPs while the C-terminus of AN contains a plant specific region. Like CtBPs, AN harbors a predicted $\operatorname{NAD}(\mathrm{H})$ binding domain in its $\mathrm{N}$-terminus that, however, carries a few mutations at positions important for binding $\mathrm{NAD}(\mathrm{H})$. The overall structure of $\mathrm{AN}$ is conserved in plants and the functional conservation has been demonstrated for homologs from several species by the complementation of the an mutant phenotype (Cho et al., 2005; Lin et al., 2008; Minamisawa et al., 2011). A functional role of the $\operatorname{NAD}(\mathrm{H})$ binding domain is suggested by the observation that an amino acid exchange in the predicted $\mathrm{NAD}(\mathrm{H})$-binding domain at position 170 from glycine to aspartic acid leads to a null-mutant phenotype (an-doq) (Fulton et al., 2009; Bai et al., 2013). A possible function for AN as a transcriptional co-repressor is supported by the finding that several genes are misregulated in an mutants (Kim et al., 2002; Fulton et al., 2009). On the other hand, a molecular function as a co-repressor appears to be unlikely as AN does not interact with adenovirus E1A protein and cannot repress the expression of reporter genes in transgenic drosophila embryos (Stern et al., 2007). In addition, it was shown that AN functions outside the nucleus and is possibly involved in membrane trafficking due to its partial trans-Golgi localization (Minamisawa et al., 2011).

AN fused to GFP under the control of the $35 \mathrm{~S}$ or the native promoter localizes to a few very bright and big dots and a few smaller dots with much weaker florescence (Minamisawa et al., 2011). The smaller dots were shown to partially co-localize with the trans-Golgi network marker VHA-al (Minamisawa et al., 2011) and this localization was confirmed by immunoelectron microscopy using the $\alpha$-AN antibody (Minamisawa et al., 2011). The bigger brighter dots were initially believed to be nuclei due to their large size (Folkers et al., 2002; Kim et al., 2002) but a subsequent report ruled them out as nuclei (Minamisawa et al., 2011). These dots were not affected by BFA treatment and did not localize with any of the tested organelle marker (Minamisawa et al., 2011). As these big aggregates were also not detected by immuno-electron microscopy using an $\alpha$-AN antibody, they were proposed to be non-physiological aggregates (Minamisawa et al., 2011). For this reason, we did not consider the big bright AN aggregates in our present study.

The molecular function of AN largely remains elusive. One way to explore its function is the identification and analysis of its interaction partners. In this study, we report $\mathrm{AN}$ to interact with several stress granule components and to localize to stress granules (SGs). Cells respond to various stress conditions by rapid and global reprogramming of gene expression at the levels of transcription, post-transcription and translation. Posttranscription regulation is typically governed by RNA-binding proteins (RBPs) that are often associated with microscopically visible mRNA-ribonucleoprotein (mRNP) complexes (BaileySerres et al., 2009) including SGs and Processing bodies (P-bodies). RBPs dynamically interact with single/double strand RNAs and mediate mRNA maturation, localization, stability, decay and translation (Dreyfuss et al., 2002; Bailey-Serres et al., 2009; Ambrosone et al., 2012). SGs form in response to stress, and function as sequestering sites for untranslated mRNAs (Anderson and Kedersha, 2008, 2009; Buchan and Parker, 2009; Kedersha et al., 2013). They have been shown to be important for cell survival by preventing accumulation of misfolded proteins and sequestering some apoptosis regulatory factors (Arimoto et al., 2008; Kedersha et al., 2013; Arimoto-Matsuzaki et al., 2016). SGs are highly dynamic and undergo dissolution upon restoration to normal conditions. In mammals, SG assembly has been shown to be triggered by phosphorylation of eIF2a under stress conditions by stress sensing kinases which leads to a depletion the eIF2/ tRNAi Met/GTP ternary complex that is required for translation initiation (Kedersha et al., 2002; Kimball et al., 2003). RBPs such as the T-cell intracellular antigen 1 (TIA-1), Ras-GAP SH3 domain-binding protein (G3BP) and TRISTETRAPROLIN (TTP) promote SG formation through low affinity interactions between intrinsically disordered regions present in these proteins (Kedersha et al., 2013). In plants only few factors are known to control SG formation (Sorenson and Bailey-Serres, 2014; Gutierrez-Beltran et al., 2015). OLIGOURIDYLATE BINDING PROTEIN 1 (UBP1), RNA-BINDING PROTEIN 45 and 47 (RBP45/47), and PAB (poly-A binding) protein families were recognized as the plant RBPs most closely related to animal TIA-1 (Sorenson and Bailey-Serres, 2014). However, the mechanism of mRNP formation and their composition largely remains unexplored in plants. Several proteins with putative RNA binding or modification activity are unique to plants and hence might have a plant-specific function (Lorković and Barta, 2002; Lorkovic, 2009).

\section{MATERIALS AND METHODS}

\section{Plant Lines and Growth Conditions}

Arabidopsis (Arabidopsis thaliana) plants were grown on soil at $24^{\circ} \mathrm{C}, 16 \mathrm{~h}$ light per day. The following lines were used: Landsberg erecta (Ler), Columbia-0 (Col-0), an-2 (Kim et al., 2002), an-1 (Kim et al., 2002), an-doq (Bai et al., 2013), 35S:PAB2-RFP [kindly provided by Prof. Julia Bailey-Serres, University of California, Riverside (Sorenson and Bailey-Serres, 2014)] and new lines established in this study including 35S:YFP-AN, 35S:AN-YFP, 35S:YFP-AN ${ }^{\text {DOQ1 }}$, 35S:YFP-AN ${ }^{\text {GAD }} \rightarrow$ VVA $, 35 S: Y F P-U B P 1 B$, and 35S:YFP-EIF4E1. N-terminal YFP and C-terminal YFP fusions were created by recombination of the corresponding entry clones with the gateway destination vectors pENS-G-YFP and pEXS-G-YFP (Feys et al., 2005). Transformation of Arabidopsis 
thaliana was done by the Floral Dip method (Clough and Bent, 1998) and transgenic plants were selected in the T1 by Glufosinat $\left(\mathrm{BASTA}^{\circledR}\right)$.

\section{Constructs}

CDSs of all the genes were amplified from Col- 0 cDNA and cloned through BP recombination in pDONR201 or pDONR207 (Invitrogen), sequenced and introduced into destination vectors by LR reactions (Invitrogen). List of constructs and primers used in this study with the AGI code are provided in the Supplementary Table S3. Mutant entry clones for $\mathrm{AN}^{\mathrm{DOQ}}$ and $\mathrm{AN}{ }^{\mathrm{GAD}} \rightarrow \mathrm{VVA}$ were created by site-directed mutagenesis. $\mathrm{AN}^{\mathrm{DOQ}}$ has a $\mathrm{G} 170 \rightarrow \mathrm{D}$ mutation mimicking the an-doq allele (Bai et al., 2013). AN $\mathrm{GAD} \rightarrow \mathrm{VVA}$ has mutations at three sites important for NADH binding: G170 $\rightarrow \mathrm{V} ; \mathrm{A} 175 \rightarrow \mathrm{V}$ and $\mathrm{D} \rightarrow$ 193A. For Lumier, the destination vectors pcDNA3-RlucGW and pTREXdest30 (Invitrogen) were used which enable the N-terminal fusion of Renilla reniformis and Staphylococcus aureus proteins, respectively, and were described in detail before (Pesch et al., 2013; Pesch et al., 2015). Protein fusions were expressed in the human HEK293TN cells.

\section{Transformation of Arabidopsis Cell Culture and Purification}

Dark grown Arabidopsis cell culture (wild-type Ler) was transfected with pENSG 35S:YFP-AN-strep transformed in Agrobacterium strain GV3101-pMP90RK as described before (Pesch et al., 2014) and grown at $22^{\circ} \mathrm{C}$ and $120 \mathrm{rpm}$ in the dark for 5 days. The cells were harvested, pellets were crushed in liquid nitrogen, and protein crude extracts were prepared by homogenizing the cell pellets in $500 \mathrm{ml}$ protein extraction buffer [50 mM Tris pH 7.5; 150 mM NaCl; 1 mM EDTA; 10\% Glycerol; $5 \mathrm{mM}$ DTT; $1 \%$ protease inhibitor cocktail (cOmpletes ${ }^{\mathrm{TM}}$, Roche); phosphatase inhibitor cocktail (PhosSTOP ${ }^{\mathrm{TM}}$, Roche); $1 \%$ Triton-X100]. After two centrifugation steps $(12,000 \mathrm{rpm}$, $\left.4^{\circ} \mathrm{C}, 20 \mathrm{~min}\right)$ the supernatant was incubated with Strep-Tactin ${ }^{\circledast}$ MacroPrep (IBA) for $1 \mathrm{~h}$ followed by five washings (lysis buffer without Triton-X100 and Glycerol). The protein was eluted using $2.5 \mathrm{mM}$ desthiobiotin containing elution buffer.

\section{Pulldown Experiment Using LUMIER}

Luminescence Based Mammalian Interactome System (LUMIER) assays were done as described previously (Pesch et al., 2013, 2015). Luciferase activity was determined before (input) and after the pulldown. Cells transformed with empty vectors served as a negative control. Percentage pulldown efficiency was calculated by: [relative luminescence unit pulldown/(relative luminescence unit input)] $\times 100$.

\section{Confocal Imaging}

We used the Leica TCS-SP8/SPE confocal microscope equipped with the LCS software. Images were made using 20 or $40 \mathrm{x}$ water/oil immersion objectives. YFP was excited at $488 \mathrm{~nm}$ and detected at 510-560 nm. RFP was excited at $561 \mathrm{~nm}$ and detected in the $580-650 \mathrm{~nm}$ range. ImageJ was used for particle count/size analysis from maximum projections of $Z$ series. Laser intensity, brightness and contrast settings were kept the same for an unbiased analysis for the particle count in wild-type and mutant backgrounds. For particle analysis, we considered granules between 0.185 and $5 \mu \mathrm{m}^{2}$ to exclude the background and nuclear signal from the images. Co-localization analysis was performed by calculating Pearson's coefficient (Adler and Parmryd, 2010; Dunn et al., 2011) using the JACOP plugin of ImageJ. Z-stack images were obtained and merged to maximum projection. For quality control, the threshold was set for each image manually such that background noise, but not distinct aggregates were eliminated. Analysis was performed on the entire image. Microscopic settings for the localization of AN were chosen to enable a safe visualization of the weakly labeled granules allowing signal saturation in the big, strongly fluorescent AN granules that were not considered in our analysis.

\section{Salt and Osmotic Stress Treatment of Seedlings}

Seeds were sterilized and plated on 1/2 MS medium and stratified for 4 days at $4^{\circ} \mathrm{C}$ in the dark and transferred to normal growth conditions. After 5 days, seedlings were transferred to medium supplemented with $150 / 175 \mathrm{mM} \mathrm{NaCl}$ for analyzing salt tolerance and 200/250 mM mannitol for analyzing osmotic stress tolerance. Six and nine days after transfer to $\mathrm{NaCl}$ or mannitol media, seedlings were analyzed for tolerance to stress conditions by analyzing cotyledon greening and root length under stress/non-stress conditions. Root length was measured using ImageJ.

\section{Transient Expression Assay}

Transfection of Arabidopsis leaves was performed by biolistic transformation (Mathur et al., 2003) and analyzed after 12-16 h by Confocal Laser Scanning Microscopy (CLSM).

\section{Yeast Two-Hybrid}

pACT2 and pAS2 plasmids (Clontech) were used for the fusion of the proteins with GAL4 activation domain and GAL4 DNA binding domain respectively. Yeast two-hybrid assays were done as previously described (Gietz et al., 1995) and interactions were analyzed on synthetic dropout medium without leucine, tryptophan, and histidine supplemented with varying concentrations of 3-aminotriazole (3-AT).

\section{Mass Spectrometry}

Mass spectrometry analysis was performed as described previously (Borgal et al., 2014; Hosseinibarkooie et al., 2016). Sample analysis was performed on an LTQ Orbitrap Discovery mass spectrometer (Thermo Scientific) coupled to an EASYnLC II nano-LC system (Proxeon, part of Thermo Scientific).

\section{Accession Numbers of Genes Expressed in Stable Lines}

AN (AT1G01510), PAB2 (AT4G34110), UBP1B (AT1G17370), EIF4E1 (AT4G18040). 


\section{RESULTS}

\section{AN Protein Physically Interacts with RNA Binding Proteins}

In an attempt to understand the molecular function of $\mathrm{AN}$ in more detail, we searched for proteins interacting with AN using the yeast two-hybrid screens. Although we performed several screening rounds with the full length AN protein as a bait on different libraries, we isolated only two interactors, ANGUSTIFOLIA INTERACTING KINASE (AIK1, AT3g17750) and Asymmetric Leaf Enhancer 3 (AE3, AT5g05780). In parallel, we performed a pulldown experiment using an Arabidopsis cell culture expressing N-terminal YFP tagged AN with a Strep tag at the C-terminus. AN was affinity purified using Strep-tactin resin and co-purified proteins were analyzed by mass spectrometry. We identified 62 co-precipitated proteins from AN expressing cell cultures that were not found in the control cell culture (Supplementary Tables S1, S2). We noted that 12 co-purified proteins are predicted to be associated with RNA metabolism suggesting that AN might be involved in the regulation of the RNA metabolism (Table 1). To test this further, we studied the protein-protein interactions of $\mathrm{AN}$ with selected proteins in quantitative pulldown experiments in HEK cells (Table 1), using the LUMIER (Barrios-Rodiles et al., 2005; Pesch et al., 2013). In short, a Prot-A tagged protein is co-transfected with Renilla reniformis luciferase in HEK cells and the amount of the interacting protein is determined after co-immunoprecipitation by a quantitative analysis of the luminescence (Barrios-Rodiles et al., 2005). The AN protein was always used as a luciferase-fusion and the putative interactors as Prot-A fusions. We chose seven RNA associated proteins that we isolated in the AN pulldown and 16 well-established RBPs chosen from the literature for the interaction studies (Table 1). In addition, we included the yeast two-hybrid interactor AIK1 as it is homologous to dual-specificity tyrosine phosphorylation-regulated kinase 3 (DYRK3) which was shown to control the dissolution of SGs in mammals through its role in mTOR signaling (Wippich et al., 2013). As summarized in Table 1, we found direct interaction with several but not all RNA associated proteins including RNA BINDING PROTEIN 47B (RBP47B; AT3G19130), RNA BINDING PROTEIN 47C (RBP47C; AT1G47490), RNA BINDING PROTEIN 47C' (RBP47C'; AT1G47500), EUKARYOTIC INITIATION FACTOR 4E1 (EIF4E1; AT4G18040), EIF(iso)4E (AT5G35620), TANDEM ZINC FINGER 3 (TZF3; AT4G29190), ARGONAUTE1 (AGO1; AT1G48410), POLY(A)BINDING PROTEIN 2 (PAB2; AT4G34110), ANGUSTIFOLIA INTERACTING KINASE (AIK1, AT3g17750).

\section{AN Localizes to Cytosolic Granules upon Different Stress Treatments}

Our LUMIER data show that AN binds to several proteins localizing to mRNP complexes. mRNP complexes are typically formed under stress conditions (Kedersha et al., 2005; Weber et al., 2008). We therefore investigated the localization of $\mathrm{AN}$ before and after different stress treatments. Previous reports have demonstrated that 35S:AN-GFP shows the same intracellular localization as ANp:AN-GFP and completely rescues the an mutant phenotype (Minamisawa et al., 2011). In this study, we established two lines expressing either AN-YFP or YFP-AN under the $35 \mathrm{~S}$ promoter in the an-2 mutant background. These lines exhibit complete phenotypic rescue. Under normal conditions, both lines showed low cytoplasmic signal and one or few bright dots along with a few smaller dots showing weaker fluorescence, similar as reported before (Minamisawa et al., 2011). In a first experiment, we applied heat stress $\left(39^{\circ} \mathrm{C}\right)$ to rosette leaves of AN-YFP plants for $40 \mathrm{~min}$ (GutierrezBeltran et al., 2015). When comparing leaves before and after the treatment we found the formation of many new cytosolic granules after heat stress (Figures 1A,B). The response to salt, osmotic and hypoxia was analyzed in the cotyledons of 5-7 days old seedlings grown on agar plates. Plants were transferred to depression slides and stress was induced by adding $1 / 2 \mathrm{MS}$ solution containing $175 \mathrm{mM}$ sodium chloride for salt stress conditions, $800 \mathrm{mM}$ sorbitol (Wippich et al., 2013) for osmotic stress and 8 units/ml oxyrase for the induction of hypoxia (Sorenson and Bailey-Serres, 2014; Lokdarshi et al., 2016). All treatments caused the formation of many cytosolic granules (Figures 1C-H). Control experiments with $1 / 2$ MS did not show a change in AN localization behavior (Supplementary Figure S1). We did not observe any differences in the recruitment behavior to granules between the $\mathrm{C}$ - and $\mathrm{N}$ - terminal fusions (AN-YFP and YFP-AN).

\section{AN Co-localizes with Several mRNP Granule Associated Proteins to Stress Granules upon Heat Stress}

The stress dependent formation of AN-labeled granules combined with our finding that $\mathrm{AN}$ protein binds to RNAassociated proteins prompted us to test, whether AN localizes to mRNP granules or SGs. Toward this end, we co-expressed established XFP-labeled SG markers with XFP-AN in single epidermal cells in Arabidopsis rosette leaves by particle bombardment. We selected four established SG markers: PAB2 (Sorenson and Bailey-Serres, 2014), UBP1B (Weber et al., 2008; Sorenson and Bailey-Serres, 2014), RBP47C (Weber et al., 2008; Lokdarshi et al., 2016) and EIF4E1 (Weber et al., 2008). For the analysis of the co-localization of PAB2 (Sorenson and BaileySerres, 2014) and UBP1B (Weber et al., 2008; Sorenson and Bailey-Serres, 2014) we analyzed the same cell before and after 40 min heat stress $\left(39^{\circ} \mathrm{C}\right.$ ) (Figure 2). After heat stress, we found a prominent co-localization of $\mathrm{AN}$ with both RNP-markers in small granules (Figures 2A,B). Similar results were obtained for the co-localization of AN with RBP47C (Supplementary Figure S2A; Weber et al., 2008; Lokdarshi et al., 2016) and EIF4E1 (Supplementary Figure S2B; Weber et al., 2008). Together these data indicate that AN protein can be recruited to SGs in a heat stress dependent manner. To determine whether AN localizes specifically to SGs or more generally to mRNP granules, we studied its co-localization with P-body marker DCP1. While SGs are thought to function as sites for transient RNA storage, P-bodies serve as platforms for RNA processing 
TABLE 1 | AN interacts with several RNA associated proteins.

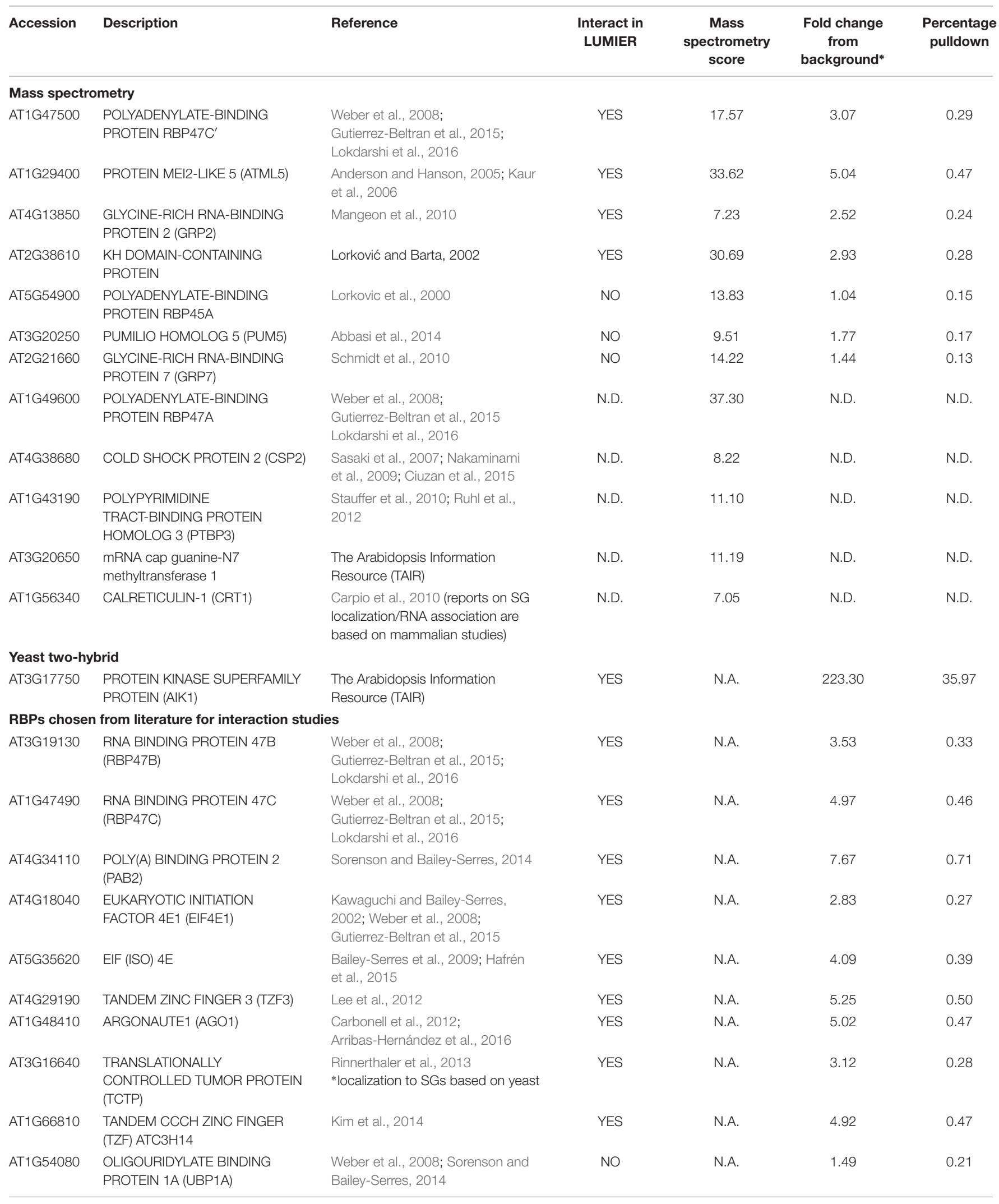


TABLE 1 | Continued

\begin{tabular}{|c|c|c|c|c|c|c|}
\hline Accession & Description & Reference & $\begin{array}{l}\text { Interact in } \\
\text { LUMIER }\end{array}$ & $\begin{array}{c}\text { Mass } \\
\text { spectrometry } \\
\text { score }\end{array}$ & $\begin{array}{l}\text { Fold change } \\
\text { from } \\
\text { background* }\end{array}$ & $\begin{array}{l}\text { Percentage } \\
\text { pulldown }\end{array}$ \\
\hline AT1G17370 & $\begin{array}{l}\text { OLIGOURIDYLATE BINDING } \\
\text { PROTEIN 1B (UBP1B) }\end{array}$ & $\begin{array}{l}\text { Weber et al., 2008; Sorenson and } \\
\text { Bailey-Serres, } 2014\end{array}$ & NO & N.A. & 0.86 & 0.08 \\
\hline AT3G14100 & $\begin{array}{l}\text { OLIGOURIDYLATE BINDING } \\
\text { PROTEIN 1C (UBP1C) }\end{array}$ & $\begin{array}{l}\text { Weber et al., 2008; Sorenson and } \\
\text { Bailey-Serres, } 2014\end{array}$ & NO & N.A. & 0.94 & 0.09 \\
\hline AT5G13570 & DECAPPING PROTEIN 2 (DCP2) & Xu et al., 2006; Weber et al., 2008 & NO & N.A. & 1.63 & 0.13 \\
\hline AT1G08370 & DECAPPING PROTEIN 1 (DCP1) & Xu et al., 2006; Weber et al., 2008 & NO & N.A. & 1.00 & 0.08 \\
\hline AT1G69440 & ARGONAUTE7 (AGO7) & Carbonell et al., 2012 & NO & N.A. & 1.78 & 0.14 \\
\hline AT1G26110 & DECAPPING PROTEIN 5 (DCP5) & Xu and Chua, 2009 & NO & N.A. & 1.09 & 0.08 \\
\hline
\end{tabular}

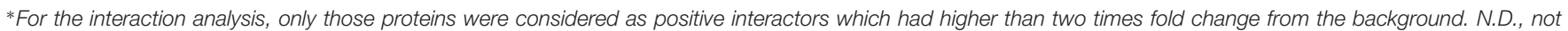
determined; N.A., not applicable.

and decay (Anderson and Kedersha, 2008). Toward this end, we co-expressed mCHERRY-AN, YFP-UBP1B and the P-body marker CFP-DCP1 (Weber et al., 2008) (Supplementary Figure S3). While AN co-localized well with UBP1B, we found no convincing co-localization with DCP1 (Supplementary Figure S3). Occasionally we noted an association of AN and DCP1 labeled granules similarly as observed for DCP1a and TIA-1 (Kedersha et al., 2005).

\section{Co-localization of AN with PAB2 in Transgenic Lines}

As the transformation of cells by particle bombardment may cause artificially high and thereby altered protein behavior, we confirmed the co-localization of the SG marker Poly-adenylate binding protein 2 (PAB2) with $\mathrm{AN}$ after stress in a stable transgenic line. PABP protein family is an integral SG component in mammals and is a universal marker for all SGs (Anderson and Kedersha, 2008). AtPAB2 has been shown to co-localize with another SG marker UBP1C (Sorenson and Bailey-Serres, 2014) and another member of PAB protein family, PAB8 has been used as a SG marker in Arabidopsis (Pomeranz et al., 2010). We crossed the YFP-AN line with the PAB2-RFP line (Sorenson and Bailey-Serres, 2014) and studied the protein co-localization in the F1 generation. As expected, YFP-AN was found in a big dot and few smaller dots and PAB2-RFP was cytoplasmic under normal conditions with (Figures 3A-C) and without YFP-AN (Supplementary Figure S4). We tested the response to heat stress in mature leaf cells and in the cotyledons of young seedlings. In both tissues we observed YFP-AN and/or PAB2-RFP positive granules (Figures 3D-I) after $40 \mathrm{~min}$ heat stress $\left(39^{\circ} \mathrm{C}\right)$, which displayed a partial co-localization. The number of granules clearly showing both signals appeared to be lower than in the particle bombardment experiments (Figures 3G-I). This notion was confirmed by a lower Pearson coefficient of co-localization $0.30 \pm 0.04$ ( $n=12$ rosette leaves), $0.34 \pm 0.4$ ( $n=8$ cotyledons) in transgenic lines as compared to transient expression experiments $(0.73 \pm 0.12, n=13)$. In our experiments we noted that both, the markers and AN can occur as singlelabeled dots. Although we cannot resolve this at this stage, this can in principle result from different threshold levels for the detection of two proteins or be explained by qualitatively different granule populations. Taken together, these results show that heat stress dependent AN co-localization with SG markers occurs, although at different degrees, in transient expression assays as well as in transgenic lines.

\section{Density and Size of SGs Is Altered in an Mutants}

In order to test, whether $\mathrm{AN}$ has a functional role in SG formation, we created transgenic marker lines expressing YFP-UBP1B and YFP-EIF4E1 under 35S promoter in an-2, an$d o q$ and the respective wild-type backgrounds. In a first step, we quantified the number of YFP-UBP1B and YFP-EIF4E1 labeled SGs after $40 \mathrm{~min}$ heat stress $\left(39^{\circ} \mathrm{C}\right)$. Cell sizes differ a lot in a given leaf and DNA content can range from $2 \mathrm{C}$ and $16 \mathrm{C}$, it is therefore difficult to interpret the number of SGs per cell. For the comparison of wild-type and an mutants, we therefore studied the density per $\mu \mathrm{m}^{2}$. This should reflect the physiologically relevant cytoplasmic density of SGs in the cells. For both markers, we found a statistically significant higher number of SGs in both an alleles as compared to the wild-type (Figure 4 and Supplementary Figure S5). This suggests that AN counteracts the formation of SGs. We additionally analyzed the size distribution of SGs in an mutants and wild-type. In both alleles we found a trend toward an increased number of smaller granules (Supplementary Figure S5). Thus, AN is required for the regulation of number and possibly the size of SGs.

\section{AN Proteins with Mutated NAD(H) Binding Domains Shows Higher Co-localization Levels with SGs}

Our finding that the an-doq mutant, which has a point mutation in the $\mathrm{NAD}(\mathrm{H})$ binding domain, displays an altered number and size of SGs, prompted us to study the function of the NAD $(H)$ binding domain in more detail. Toward this end we used two mutant proteins: $\mathrm{AN}{ }^{\mathrm{DOQ}}$, which is a mimic of an-doq mutant and $A N^{G A D} \rightarrow V V A$, which carries three amino acid exchanges in the $\mathrm{NAD}(\mathrm{H})$ domain potentially disrupting the NADH binding.

We expressed both mutant proteins as N-terminal YFP fusions in the an-2 mutant under the control of the $35 \mathrm{~S}$ promoter. Although an-doq mutant shows a null phenotype, 


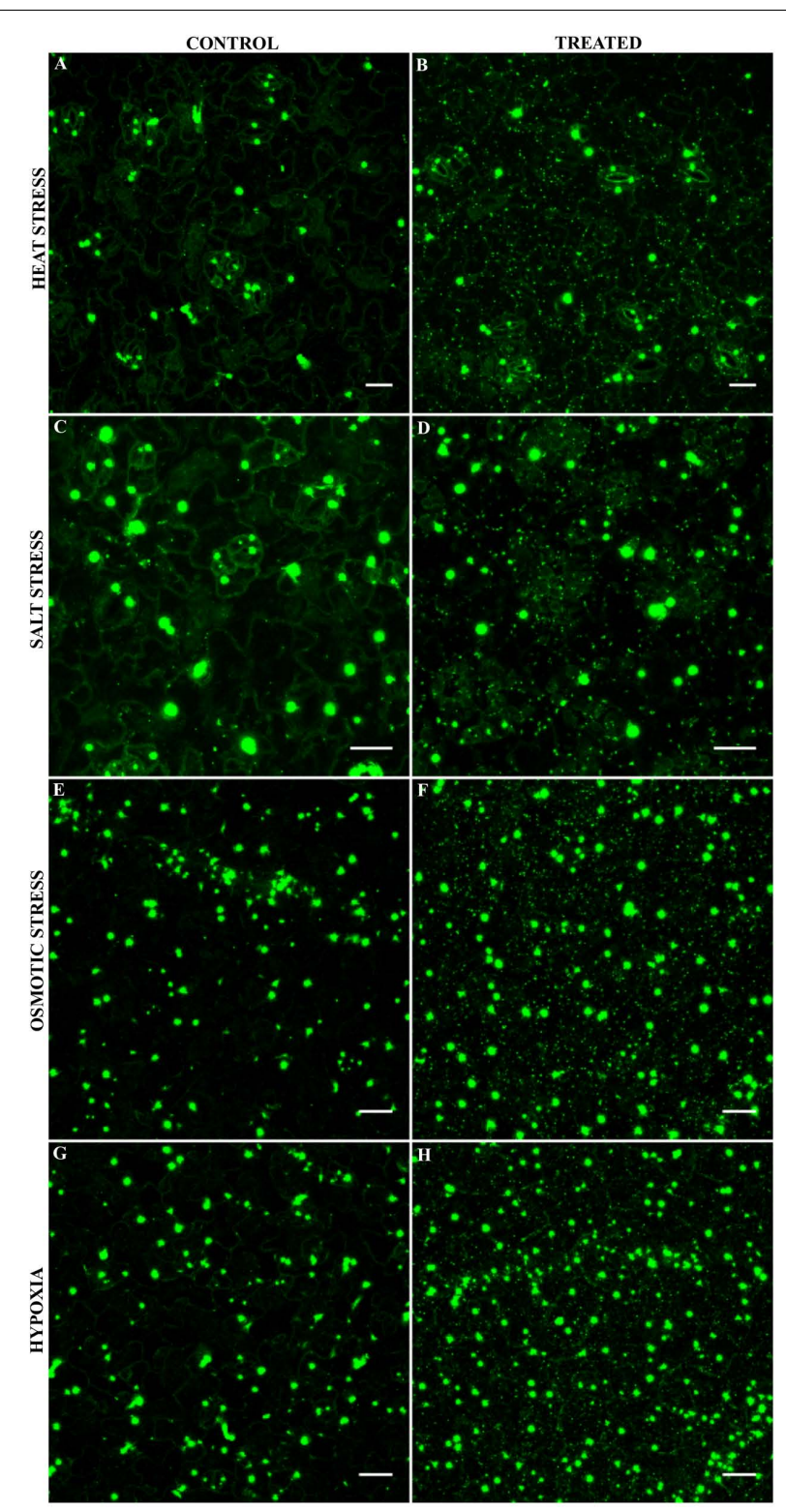

FIGURE 1 | Localization of AN-YFP under different stress conditions. Images for comparison of AN localization before and after treatments were obtained from the same leaf. Microscopic settings were chosen to enable a good visualization of the weak dots, ignoring potential saturation of the big bright dots not considered here. Rosette leaf of a 3 week old plant before (A) and after $40 \mathrm{~min}$ heat stress at $39^{\circ} \mathrm{C}$ (B). Cotyledons of 5-7 day old plants before (C) and $40 \mathrm{~min}$ after addition of $175 \mathrm{mM}$ sodium chloride (D). Cotyledons of 5-7 day old plants before (E) and 40 min after addition of $800 \mathrm{mM}$ sorbitol (F). Cotyledons of 5-7 day old plants before (G) and 40 min after addition 8 units/ml oxyrase for the induction of hypoxia $\mathbf{( H )}$. Scale bars: $20 \mu \mathrm{m}$.

overexpression of $\mathrm{YFP}-\mathrm{AN} \mathrm{DOQ}^{\mathrm{DO}}$ rescued the an-2 mutant morphological phenotypes suggesting that $A N^{D O Q}$ protein has some residual activity. In contrast, YFP-AN ${ }^{G A D} \rightarrow$ VVA overexpression showed weak rescue of the leaf length/width ratio and no rescue of the trichome phenotype (Supplementary Figure S6). Both proteins were cytoplasmic (Figures 5A,D). In contrast to wild-type AN protein (Figure 1), we found no dots under normal conditions. Upon heat stress, YFP-AN ${ }^{D O Q}$ and YFP$\mathrm{AN}^{\mathrm{GAD} \rightarrow \mathrm{VVA}}$ labeled granules were formed (Figures 5B,C,E,F). This suggests that the recruitment of both proteins to SGs can occur in the absence of wild-type AN protein.

In a next step, we analyzed the co-localization of YFP-AN ${ }^{D O Q}$ and YFP-AN $\mathrm{GAD}^{\mathrm{VVA}}$ with the SG marker PAB2 in double transgenic lines. Without stress, we observed only cytoplasmic signals (Figures 6A-C and Supplementary Figures S7A-C). After heat stress, PAB2-RFP and YFP-AN ${ }^{D O Q}$ and YFP-AN ${ }^{\mathrm{GAD}} \rightarrow$ VVA positive granules were found (Figures 6D-I and Supplementary Figures S7D-I). Strikingly, YFP-AN ${ }^{D O Q}$ and YFP-AN ${ }^{\mathrm{GAD}} \rightarrow$ VVA signals appeared to almost completely co-localize with PAB2RFP in contrast to the partial co-localization observed in case of wild-type protein (Figure 3). This visual impression was confirmed by a much higher Pearson coefficients of YFP$\mathrm{AN}^{\mathrm{DOQ}}(0.75 \pm 0.06)$ and YFP-AN ${ }^{\mathrm{GAD} \rightarrow \mathrm{VVA}}(0.77 \pm 0.09)$ with PAB2-RFP as compared to wild-type AN (Pearson coefficient: $0.30 \pm 0.04)$.

\section{The NAD(H) Domain Is Important for Differential Protein Interactions of AN Protein}

Previous reports on the role of the $\mathrm{NAD}(\mathrm{H})$ domain of CtBP in regulating its protein-protein interactions (Balasubramanian et al., 2003; Fjeld et al., 2003) prompted us to study the dimerization and interaction ability of $\mathrm{AN}^{\mathrm{DOQ}}$ and $\mathrm{AN} \mathrm{NAD}^{\mathrm{G}} \rightarrow \mathrm{VVA}$ proteins. In yeast two-hybrid assays, the dimerization of wildtype AN was observed at $3 \mathrm{AT}$ concentrations up to $30 \mathrm{mM}$ whereas we detected no dimerization between $A N^{D O Q}$ proteins (Supplementary Figure S8). To independently confirm this result, we used the LUMIER assay. Here we found a marked reduction of the interaction between $A N^{D O Q}$ proteins (Figure 7A). Similar results were obtained for the $\mathrm{AN}^{\mathrm{GAD}} \rightarrow \mathrm{VVA}$ protein (Figure 7A). In order to determine, whether the $\operatorname{NAD}(\mathrm{H})$ domain mutant proteins are generally impaired in protein-protein interactions or whether only specific protein interactions depend on this domain, we studied the interaction of $A N^{D O Q}$ with five $\mathrm{AN}$-interactors including AIK1, AGO1, RBP47B, PAB2, and $\mathrm{EIF}$ (iso)4E. We found a drastically reduced interaction of $A N^{\mathrm{DOQ}}$ with AIK1 (Figure 7B) (reduced to $1.6 \%$ of wild-type AN). However, we did not detect significant changes in interaction ability with AGO1, RBP47B, PAB2 and EIF(iso)4E (Figure 7B). This indicates that the $\mathrm{NAD}(\mathrm{H})$ binding domain of $\mathrm{AN}$ is relevant for some but not all interactions.

\section{AN Is Involved in Salt and Osmotic Stress Responses in Plants}

Our findings that AN is recruited to SGs upon stress treatment and its role in regulating SG number and size raised the question whether $\mathrm{AN}$ has, in addition to the well-reported cell morphogenesis phenotypes, also a role in stress responses. First evidence for a role of $\mathrm{AN}$ in biotic and abiotic stress tolerance was reported by Gachomo et al. (2013). In this study, we chose salt and osmotic stress: two conditions under which we observed AN recruitment to SGs and for which standardized treatments 


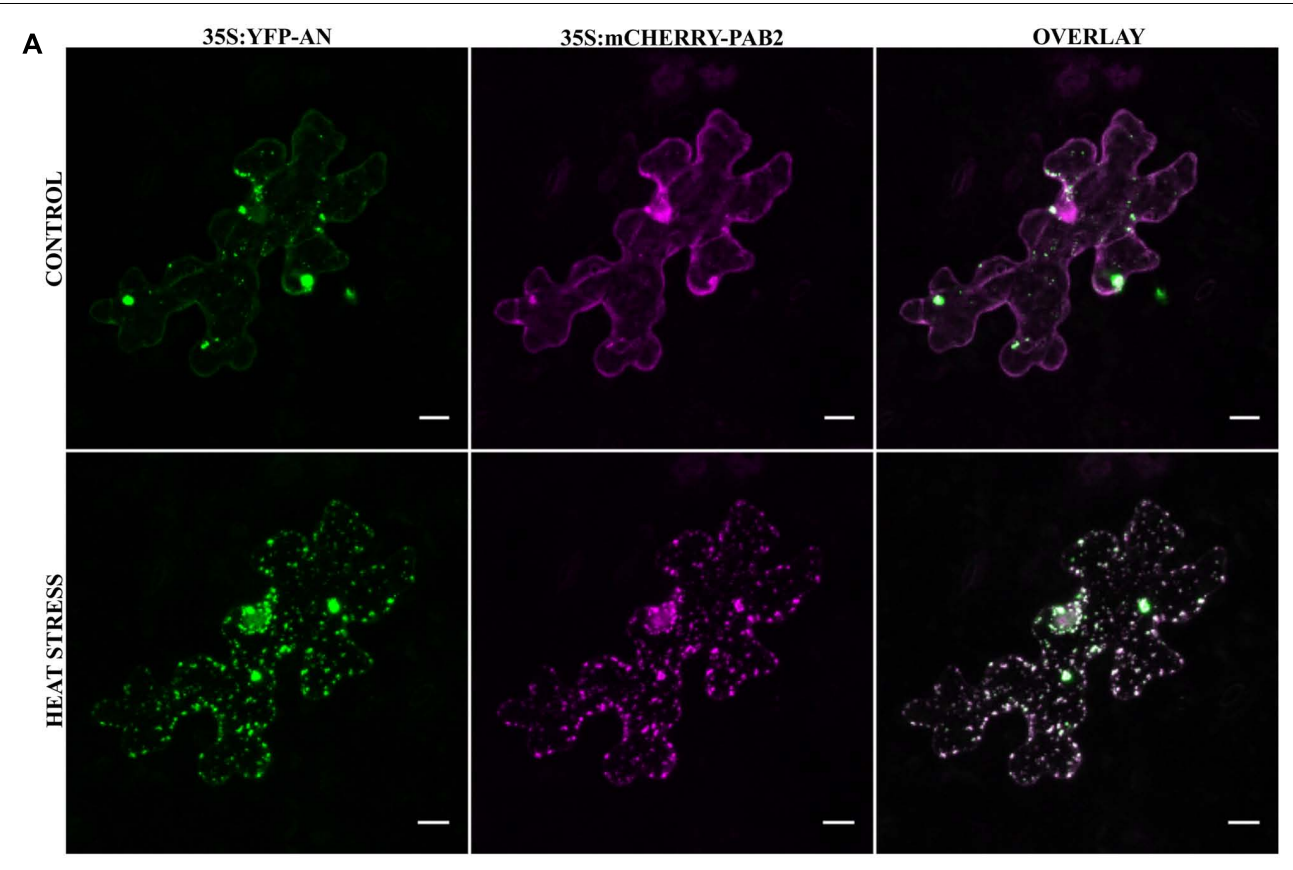

B

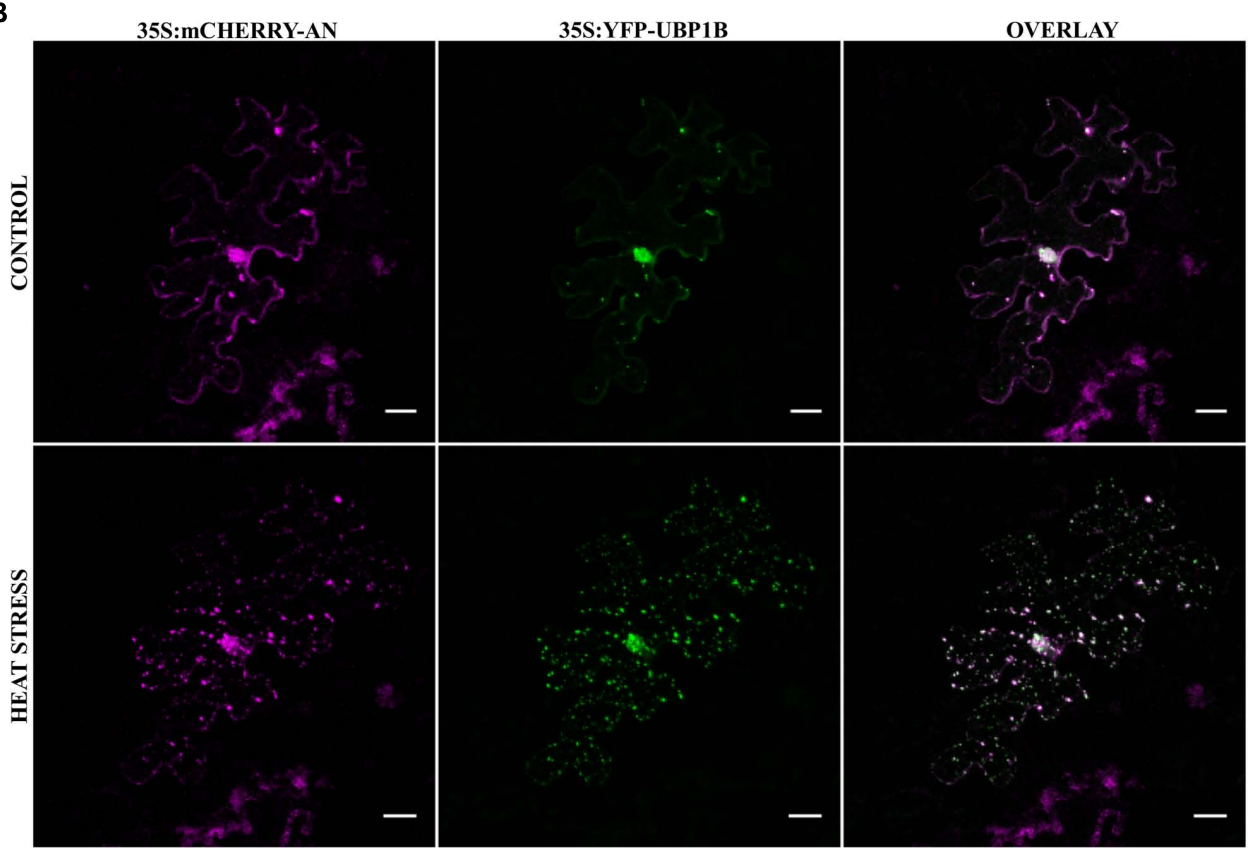

FIGURE 2 | Co-localization of AN with RNA-binding proteins before and after heat stress. Co-localization studies were done in transiently transformed Arabidopsis rosette leaves by particle bombardment. (A) Single epidermal cell showing the localization of YFP-AN (green) and mCHERRY-PAB2 (red) before and after heat stress. Co-localization of the proteins appears white in the overlay. Scale bar: $10 \mu \mathrm{m}$. (B) Single epidermal cell showing the localization of mCHERRY-AN (red) and

YFP-UBP1B (green) before and after heat stress. Co-localization of the proteins appears white in the overlay. Scale bar: $20 \mu \mathrm{m}$. Pearson coefficients of $0.73 \pm 0.12$ $(n=13)$ and $0.82 \pm 0.07(n=14)$ were obtained for co-localization analysis of AN with PAB2 and UBP1B respectively.

are well-established. an mutants and wild-type plants were grown on $1 / 2$ MS plate supplemented with different concentration of salt or mannitol. After 6-9 days of growth, the primary root length and the greening of the cotyledons was compared between non-treated and stress treated seedlings. At 150 and $175 \mathrm{mM}$
$\mathrm{NaCl}$ concentrations an mutants displayed hyposensitivity to salt stress (Figure 8). an mutants showed longer roots and greener cotyledons as compared to wild-type. Similarly, an mutants were less sensitive than wild-type to 200 and $250 \mathrm{mM}$ mannitol treatments (Figure 8). 


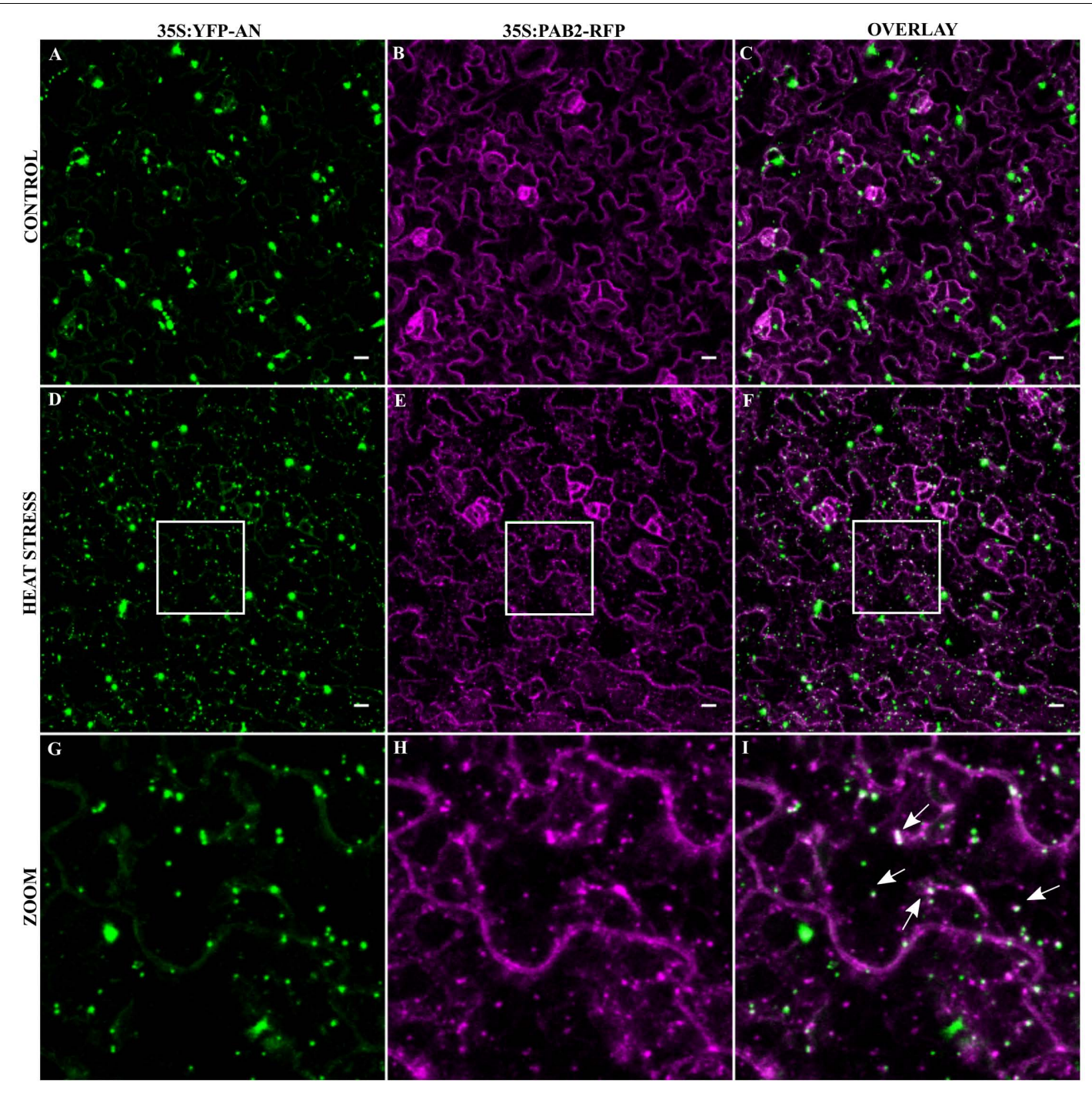

FIGURE 3 | Co-localization of YFP-AN with PAB2-RFP in transgenic lines. Cotyledons from 5 to 7 days old seedlings of a 35S:YFP-AN and 35S:PAB2-RFP expressing plant were analyzed under normal conditions and after 40 min heat stress $\left(39^{\circ} \mathrm{C}\right)$. The YFP and RFP channels and their overlay are shown. (A-C) Control leaf before stress. (D-F) Heat stressed leaf. (G-I) Higher magnification of the boxes indicated in (D-F). Scale bar: $10 \mu \mathrm{m}$.

\section{DISCUSSION}

In this study, we provide several lines of evidence suggesting that $\mathrm{AN}$ has a role as a component of SGs. First, AN is associated with several RBPs in vivo and directly interacts with some of them (Table 1 and Supplementary Table S1). Second, AN co-localizes with RBPs to SGs upon stress (Figures 2, 3 and Supplementary Figure S2). Third, AN regulates the formation of SGs (Figure $\mathbf{4}$ and Supplementary Figure S5). The novel interaction and localization behavior of AN hence suggests that it acts as a post-transcriptional regulator.

\section{Possible Role of AN in \\ Post-transcriptional Regulation}

How can these novel findings be integrated to the current concepts on the molecular function of AN? Function and localization of $\mathrm{AN}$ has been controversial since its discovery. Some reports suggest it to be involved in transcriptional control similar as known for its mammalian homolog CtBP (Chinnadurai, 2007). In support of this, microarray analysis revealed differential gene expression between wild-type and an mutants in Arabidopsis (Kim et al., 2002; Fulton et al., 2009; Bai et al., 2013). This view is challenged by the findings that AN cannot rescue drosophila CtBP mutants (Stern et al., 2007) and functions outside the nucleus where it partially localizes to the trans-Golgi network (Minamisawa et al., 2011). Consistent with this, we found various membrane trafficking proteins in our pulldown experiments that are associated with AN (Supplementary Table S1) such as VPS34 and KEULE. Thus, AN appears to be associated with both membrane trafficking components as well as with mRNP components suggesting a dual function in the cytoplasm. 


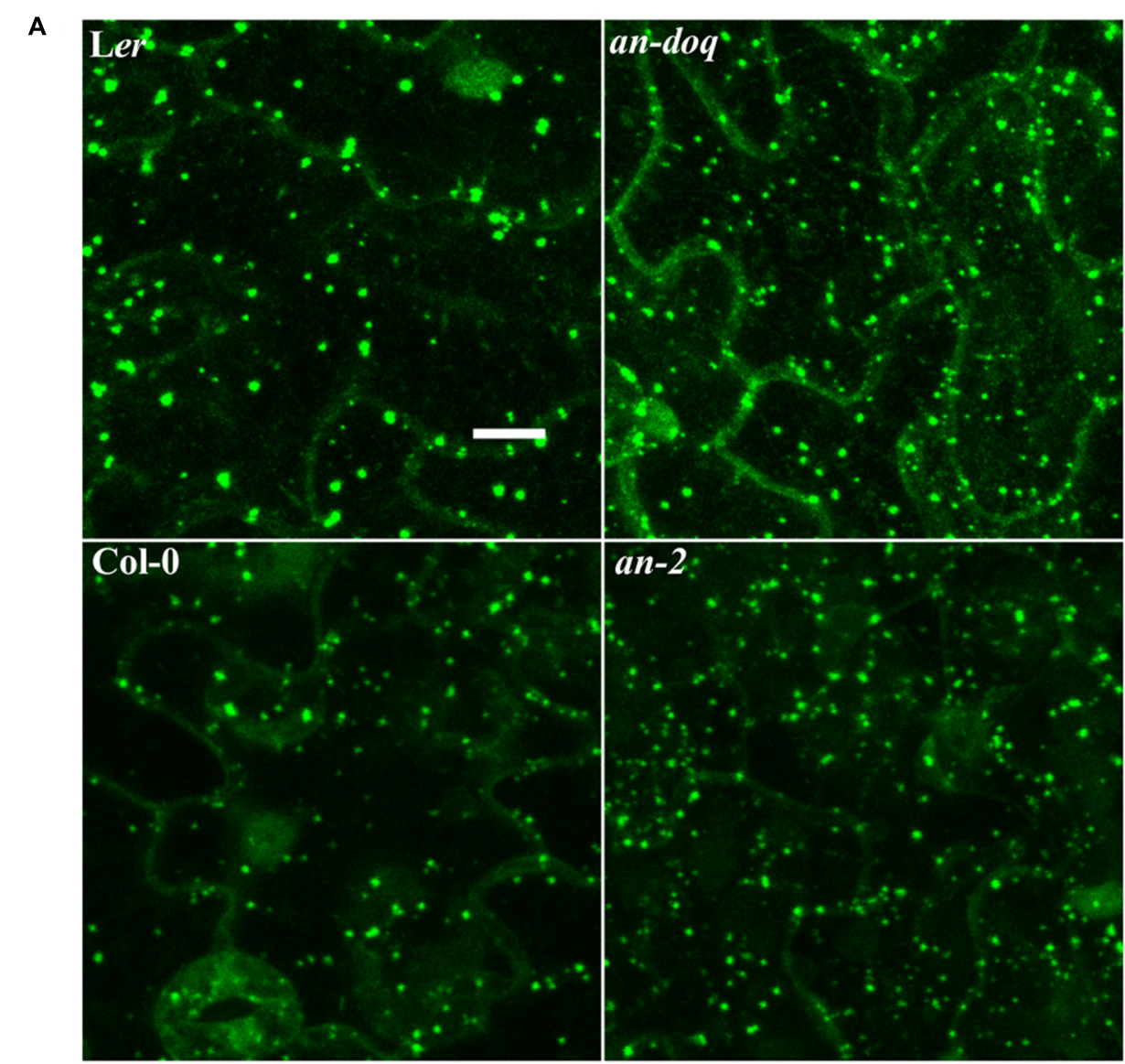

B

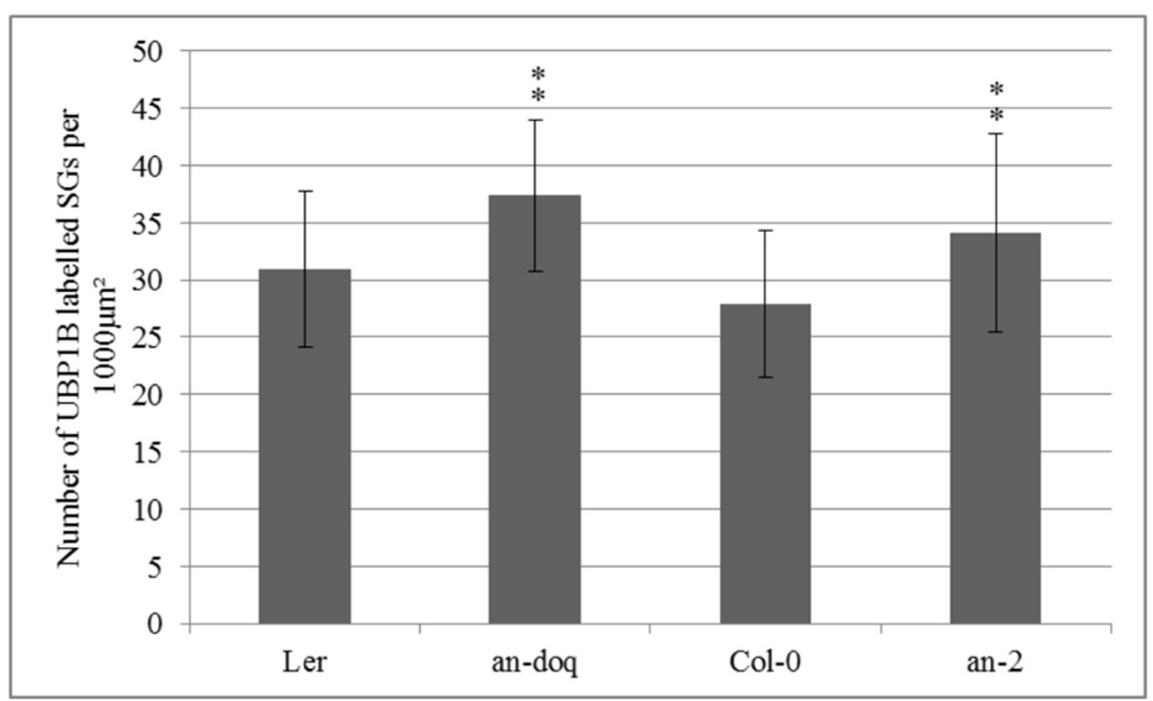

FIGURE 4 | Stress granule (SG) size and number is altered in an mutants. Transgenic lines expressing 35S:YFP-UBP1B in Ler, an-doq, Col-0 and an-2 were analyzed after 40 min heat stress $\left(39^{\circ} \mathrm{C}\right)$. The Z-stacked images were analyzed for the number and size of SGs using the Image analyze particles tool. (A) Confocal microscopy images showing formation of UBP1B labeled granules in Ler, an-doq, Col-0 and an-2 after heat stress. Scale bar: $10 \mu \mathrm{m}$. (B) Number of UBP1B labeled SGs formed upon heat stress in wild-type and an mutant backgrounds. Graphs show mean number \pm SD per $1000 \mu m^{2}$ area for $n=15 \sim 30$ seedlings; ** $p<0.01$; Student's t-test. 


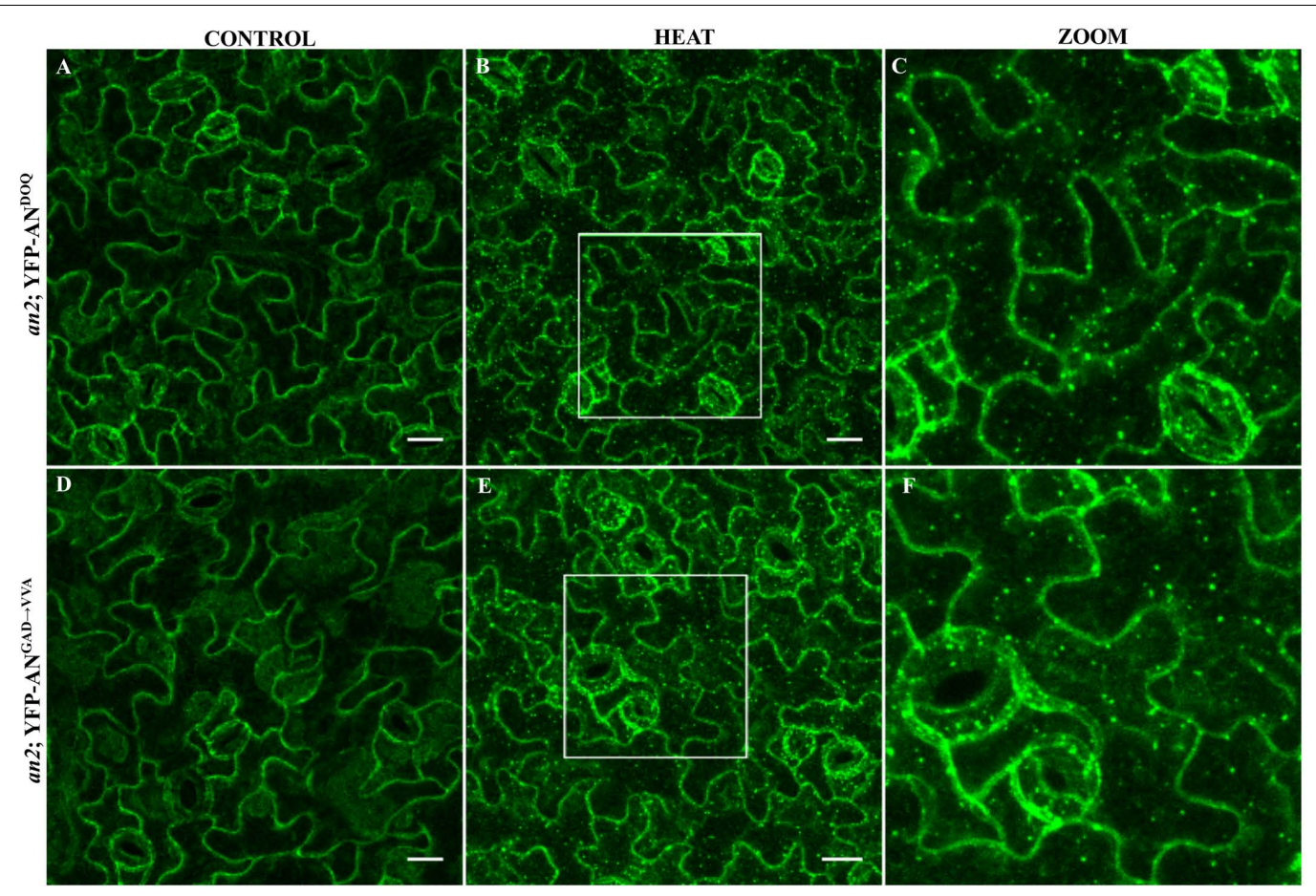

FIGURE 5 | Localization of $A N^{D O Q}$ and $A N^{G A D} \rightarrow$ WA in the an-2 mutant background. Transgenic lines expressing $Y F P-A N D O Q$ and $Y F P-A N G A D \rightarrow W A$ in the an-2 mutant background. an-2 YFP-ANDOQ leaves without stress $(\mathbf{A})$, after 40 min heat stress $\left(39^{\circ} \mathrm{C}\right)(\mathbf{B})$ and a higher magnification $(\mathbf{C})$ of the box indicated in (B). an-2 YFP-AN $N^{G A D} \rightarrow W A$ leaves without stress (D), after 40 min heat stress $\left(39^{\circ} \mathrm{C}\right)$ (E) and a higher magnification (F) of the box indicated in $(\mathbf{E})$. Scale bar: $20 \mu \mathrm{m}$.

A possible role of $\mathrm{AN}$ in $\mathrm{SG}$ is suggested by its interaction with various SG components and its localization to SGs after various stress treatments. The interactions of AN to SG components is also seen under non-stress conditions in our assays. This suggests that AN might generally interact with SG components under non-stress and stress conditions also in plant cells. Given that various SG proteins are involved in translational processes, it is possible that AN functions in the translational machinery. This would provide an elegant explanation for its broad range of functions in development, morphogenesis and biotic/abiotic stress responses. Nevertheless, our finding that SG formation is altered in an mutants indicates that AN has a relevant function in SGs (Figure 4 and Supplementary Figure S5).

\section{Function of the NAD(H) Binding Domain of AN}

A major mechanism by which CtBPs regulate transcriptional events is by their ability to bind $\operatorname{NAD}(\mathrm{H})$ which results in a conformational change in CtBPs, in turn effecting its binding to interaction partners (Balasubramanian et al., 2003; Kuppuswamy et al., 2008; Nardini et al., 2009; Zhang and Arnosti, 2011). CtBPs are proposed to act as redox sensors (Zhang et al., 2002; Fjeld et al., 2003) due to their reported higher affinity for reduced NADH dinucleotide over NAD+, hence linking cellular redox state to the transcriptional output. Also, the disruption of the $\mathrm{NAD}(\mathrm{H})$ binding site in $\mathrm{CtBPs}$ lead to reduced or abolished dimerization rates (Nardini et al., 2009; Madison et al.,
2013) and dimerization in turn is important for the regulation of co-transcriptional activity of CtBP (Madison et al., 2013). A functional role of the AN NADH binding domain is suggested by the finding that a point mutation in the $\mathrm{NAD}(\mathrm{H})$ domain results in a complete lack of function phenotype in an-doq allele (Bai et al., 2013). In this study, we found the same cellular phenotype for the stress dependent formation of SGs in an-2 and an-doq allele (Figure 4 and Supplementary Figure S5) and observed hyposensitivity of an-2 and an-doq alleles to salt and osmotic stress (Figure 8). This suggests that the $\mathrm{NAD}(\mathrm{H})$ binding domain is also important for AN function in stress responses.

As experimental evidence for a binding of $\operatorname{NAD}(\mathrm{H})$ to AN is lacking, we cannot conclude whether the $\mathrm{AN}^{\mathrm{DOQ}} / \mathrm{AN}^{r m G A D} \rightarrow \mathrm{VVA}$ mutations lead to the predicted reduced or no binding of $\mathrm{NAD}(\mathrm{H})$ to $\mathrm{AN}$ or whether they disturb the functions of the domain otherwise (e.g., stability, conformation, interaction ability). As the point mutations specifically target the positions predicted to be relevant for $\mathrm{NAD}(\mathrm{H})$ binding, it is reasonable to assume that AN activity is regulated by binding to $\mathrm{NAD}(\mathrm{H})$. As an-doq mutants display a null phenotype we propose that the $\mathrm{NAD}(\mathrm{H})$ bound form is the active form. The findings that overexpression of the $\mathrm{AN}{ }^{\mathrm{DOQ}}$ protein can fully rescue the an mutant trichome and leaf phenotypes and that overexpression of the $\mathrm{AN}{ }^{\mathrm{GAD}} \rightarrow \mathrm{VVA}$ protein can partially rescue the leaf length/width phenotype (Supplementary Figure S6) can be explained by some residual activity of the mutant proteins and that this reduced activity can be compensated by providing excess protein levels. 


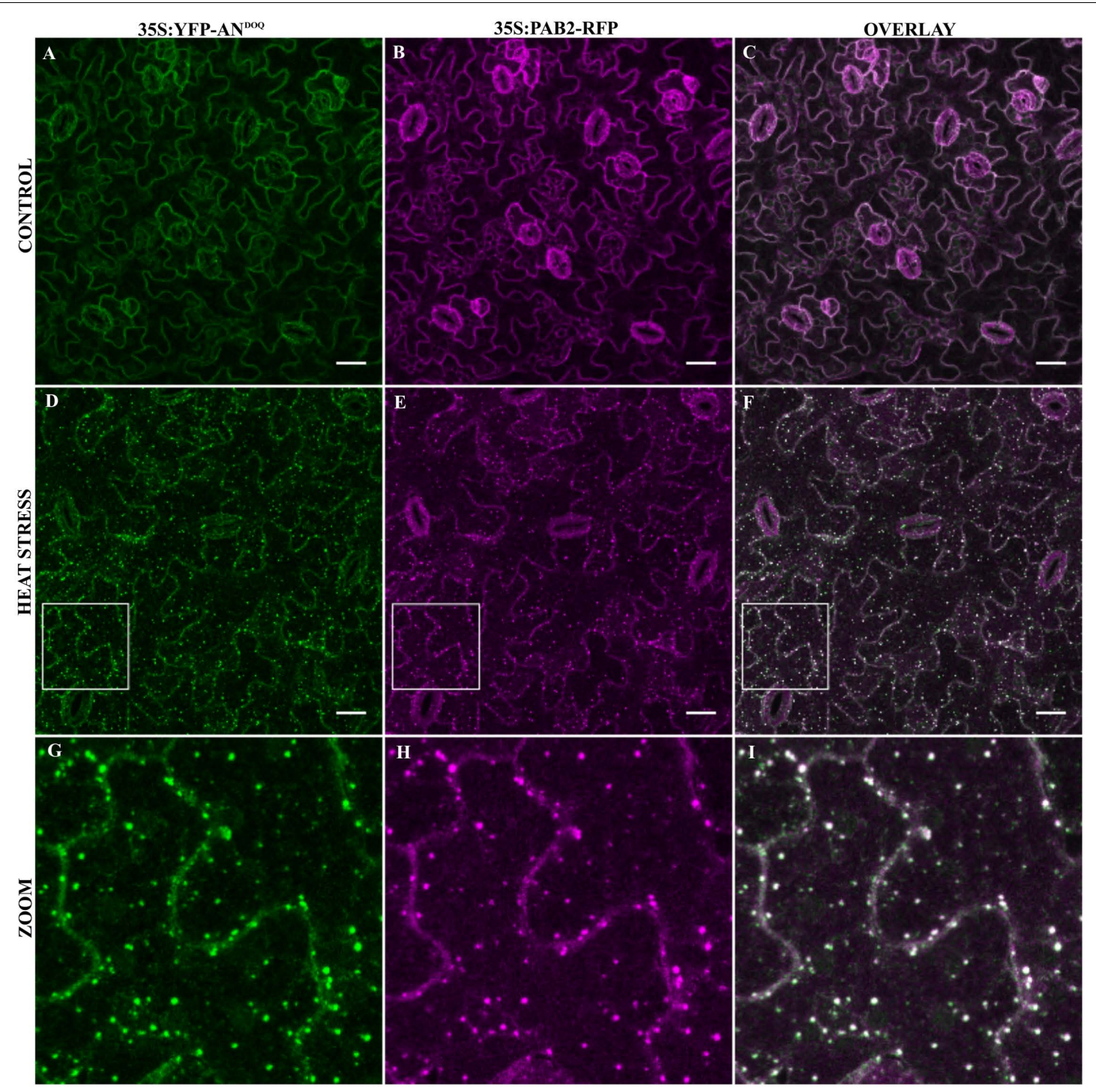

FIGURE 6 | Co-localization of YFP-ANDOQ with PAB2. Transgenic lines co-expressing YFP-ANDOQ and PAB2-RFP. YFP-ANDOQ and PAB2-RFP expressing leaf without stress (A-C), after 40 min heat stress $\left(39^{\circ} \mathrm{C}\right) \mathbf{( D - F )}$ and a higher magnification (G-I) of the box indicated in (D-F). Scale bar: $20 \mu \mathrm{m}$.

\section{Possible Role of AN in SGs}

Our data suggest that the recruitment of AN to SGs does not depend on the $\mathrm{NAD}(\mathrm{H})$ domain as YFP-AN ${ }^{\mathrm{DOQ}}$ and YFP-AN ${ }^{\mathrm{GAD}} \rightarrow$ VVA mutant proteins localize to SGs in the absence of wild-type protein (Figure 5). Both mutant proteins are evenly distributed in the cytoplasm (Figure 5). Big dots as observed with wild-type AN were not found, possibly because they represent non-physiological aggregates that do not form because the dimerization is strongly reduced in the mutant AN proteins (Figure 7A). The increased number of SGs in an mutants suggests that binding of the active form of AN counteracts the formation of SGs. It is conceivable that binding of the active form of $\mathrm{AN}$ is very transient and that this population of $\mathrm{AN}$ molecules cannot be seen in our co-localization experiments. As a consequence we would see only the inactive form of $\mathrm{AN}$ at SGs. These considerations would explain that $\mathrm{AN}^{\mathrm{DOQ}}$ and $\mathrm{AN}^{\mathrm{GAD}} \rightarrow \mathrm{VVA}$ show close to $100 \%$ co-localization with PAB2 labeled SGs while wild-type AN exhibits partial co-localization (Figure 6 and Supplementary Figure S7). Along the same line, this scenario can explain the higher co-localization levels of wildtype AN with PAB2 in bombardment experiments as compared to transgenic lines as the high levels of AN reached in bombardment experiments may result in a larger population of inactive AN molecules, due to the limited availability of cellular NADH pools. What could be the role of AN in SGs? The moderately increased number of SGs in an mutants indicates that AN can counteract their formation not as a key regulator but rather as a modulator. One attractive possibility is that AN could fine tune SG formation in a redox dependent manner by its ability to monitor the $\mathrm{NAD}^{+} / \mathrm{NADH}$ ratio similar as shown for CtBPs. 
A

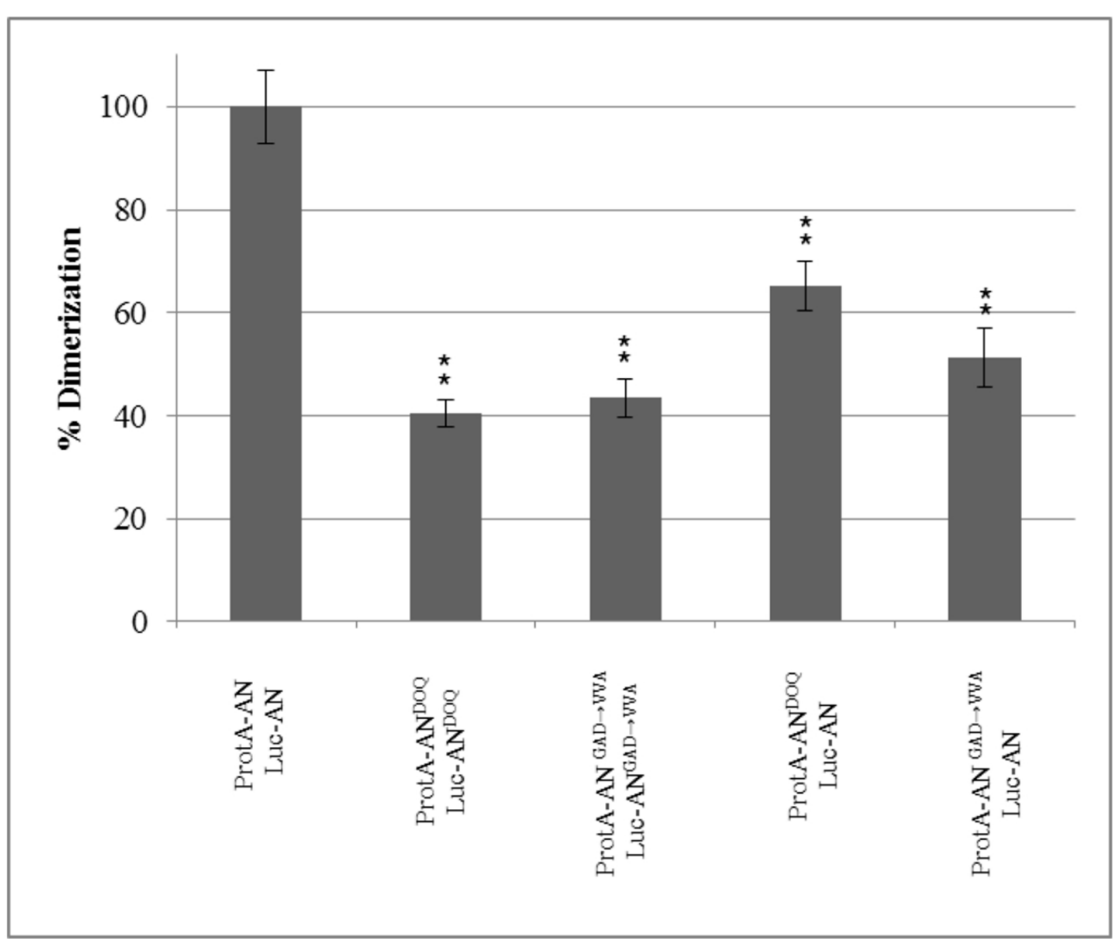

B

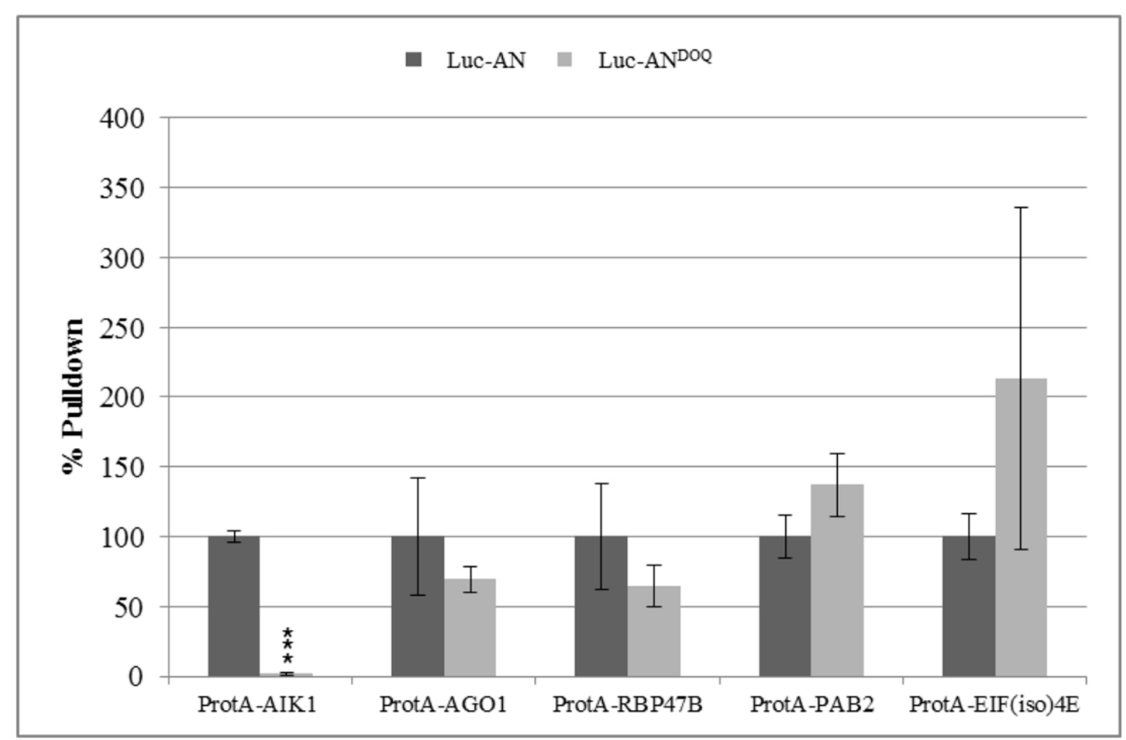

FIGURE 7 | Point mutations in NADH binding domain lead to compromised dimerization rates and a selective reduction in interaction with AlK1. Pulldown values were plotted as percentage relative to the input and normalized to wild-type pulldown rates which was set as $100 \%$. (A) Percentage dimerization efficiency of ANDOQ and $A N G A D \rightarrow W A$ proteins as compared to wild-type $A N$. Dimerization is significantly reduced for $A N^{D O Q}$ and $A N G A D \rightarrow W N$. Data is relative to wild-type which is set as 100\%. Graph summarizes different experiments and standard deviation seen for the wild-type is highest seen in the experiments. Data are mean \pm SD $(n=3)$.

(B) Interaction efficiency of $A N$ and $A N D O Q$ with some selected proteins. Interaction of $A N^{D O Q}$ with AlK1 is significantly reduced whereas we found no significant differences to wild-type AN for the interaction with AGO1, RBP47B, PAB2 and EIF(iso)4E. ** $p<0.01$; Student's $t$-test.

\section{Regulation of AN Binding to Other Proteins by the NAD(H) Domain}

A molecular basis for the functionality of $\mathrm{NAD}(\mathrm{H})$ binding domain is offered by the differential interaction of $\mathrm{AN}^{\mathrm{DOQ}}$ with itself and other proteins. While some interactions are not effected by point mutations in the $\mathrm{NAD}(\mathrm{H})$ domain, the dimerization and its interaction with AIK1 is severely reduced (Figure 7). This suggests that the NADH binding domain mediates specific binding of AN to target proteins, thereby regulating their function in RBPs. Biotic and abiotic 

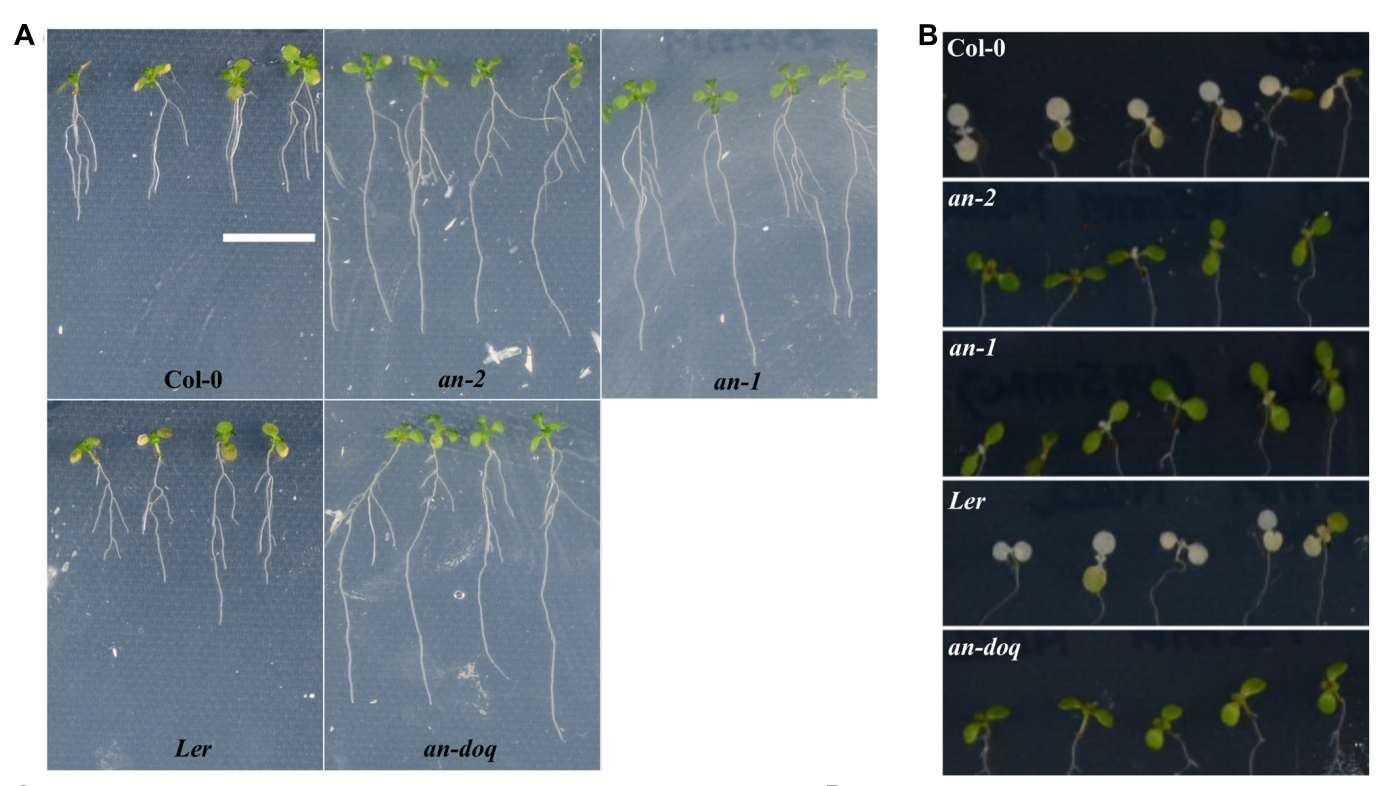

C

D
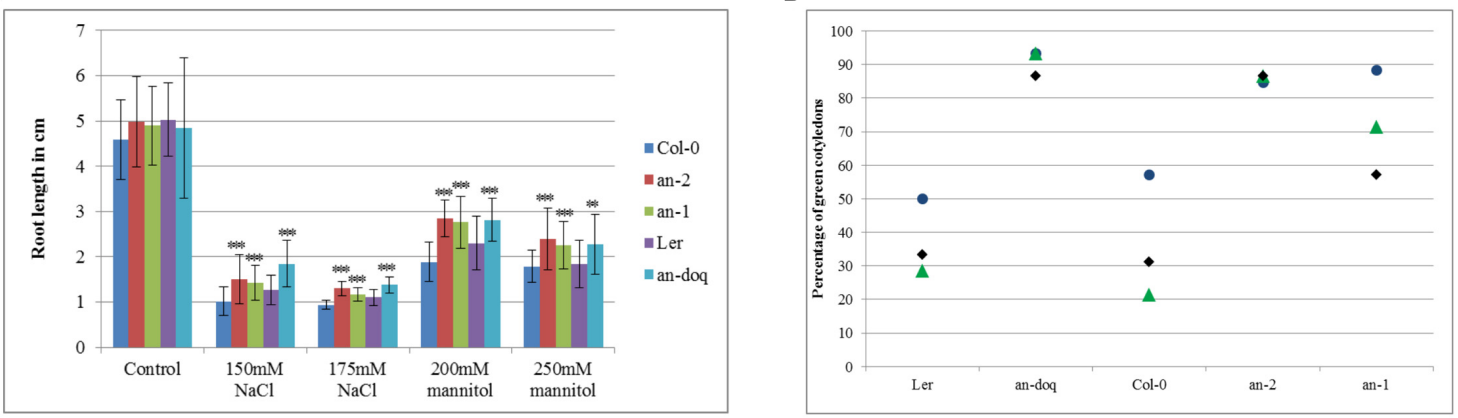

FIGURE 8 | an mutants are hyposensitive to salt and osmotic stress. 5 day old plants grown on $1 / 2$ MS were transferred to $1 / 2$ MS containing different concentrations of $\mathrm{NaCl}$ and mannitol. Responses were assessed on the basis of primary root length growth and cotyledon greening. (A) Seedlings 9 days after the transfer to $250 \mathrm{mM}$ mannitol containing media, Scale bar: $1 \mathrm{~cm}$. (B) Cotyledons of seedlings 6 days after transfer to $175 \mathrm{mM} \mathrm{NaCl}$ containing media. (C) Root length of seedlings 9 days after the transfer to $\mathrm{NaCl} /$ Mannitol containing media. More than 40 seedlings were analyzed for each condition. ${ }^{* *} p<0.01,{ }^{* * *} p<0.001$, Student's $t$-test. (D) Dot plot distribution showing cotyledon greening percentage for seedlings grown on $1 / 2 \mathrm{MS}+175 \mathrm{mM} \mathrm{NaCl}$ after 6 days. Each data point represents 13-15 seedlings per condition. Triplicates are presented for each growth condition.

stresses can lead to an increase in reactive oxygen species (ROS) levels within a cell, leading to redox imbalance and oxidative stress (Hossain et al., 2015) that in turn could be sensed by the NADH binding domain of AN. We therefore speculate that AN function is governed by the redox status of the cell which in turn controls its interaction with specific SG associated proteins and thereby, the function of SGs. This is analogous to the function of Enhancer of decapping 3 (EDC3) and Apoptosis inducing factor (AIF) in mammals, which has been postulated to control mRNP granule formation in a redox dependent manner (Candé et al., 2004; Walters et al., 2014). A structural feature known to mediate aggregation of proteins into RNA granules is the presence of an intrinsically disordered/low complexity region (Kedersha et al., 2013). Using IUPred ${ }^{1}$ we found an intrinsically disordered region in AN between amino acid 342

${ }^{1}$ http://iupred.enzim.hu/ and 487 at the N-terminus. It is therefore possible that AN can associate with SGs through such intrinsically disordered regions.

\section{Role of AN in SGs and Stress Responses in an Mutants}

Is the association of AN with mRNP granules and its role in mRNP granule formation functionally significant? AN is involved in different stress responses as an mutants are more resistant than wild-type to dehydration stress and pathogen attack (Gachomo et al., 2013). More specifically, we observed a hyposensitivity of an mutants as compared to wild-type for two stress treatments triggering a re-localization of AN- salt and osmotic stress (Figure 8). These data suggest that a role of $\mathrm{AN}$ in stress responses can be explained by a function as a component of SGs, which are typically formed in response to stress. Examples for 
a correlation between SG formation and stress response phenotype include the SG components UBP1B and Tudor staphylococcal nuclease (TSN). UBP1B has been shown to be required for SG formation in plants (Weber et al., 2008) and $u b p 1 b$ mutants are hypersensitive to salt and osmotic stress responses (McCue et al., 2012). Similarly, tsn1tsn2 mutants show reduced number of SGs and are hypersensitive to heat stress (Gutierrez-Beltran et al., 2015). The novel findings hence suggest a role of $\mathrm{AN}$ as a post-transcriptional regulator, rather than a transcriptional repressor. An attractive scenario would be a role of $\mathrm{AN}$ in balancing growth and metabolism by sensing the cellular redox states.

\section{CONCLUSION}

Our findings suggest that AN is involved in the coordination of cellular stress responses such that it regulates SG formation and possibly dissolution in a redox dependent manner. An interesting perspective for the future will be to identify direct molecular targets of $\mathrm{AN}$, through which it regulates SG formation. It will also be interesting to test whether a function of AN in SGs is evolutionary conserved in $\mathrm{CtBPs}$ given that CtBPs are potential therapeutic targets for cancer treatment and that some SG signaling proteins have been associated with tumor progression (Somasekharan et al., 2015).

\section{REFERENCES}

Abbasi, N., Park, Y.-I., and Choi, S.-B. (2014). Pumilio Puf domain RNA-binding proteins in Arabidopsis. Plant Signal. Behav. 6, 364-368. doi: 10.4161/psb.6.3. 14380

Adler, J., and Parmryd, I. (2010). Quantifying colocalization by correlation: the pearson correlation coefficient is superior to the Mander's overlap coefficient. Cytometry A 77, 733-742. doi: 10.1002/cyto.a.20896

Ambrosone, A., Costa, A., Leone, A., and Grillo, S. (2012). Beyond transcription: RNA-binding proteins as emerging regulators of plant response to environmental constraints. Plant Sci. 182, 12-18. doi: 10.1016/j.plantsci.2011.02.004

Anderson, G. H., and Hanson, M. R. (2005). The Arabidopsis Mei2 homologue AML1 binds AtRaptor1B, the plant homologue of a major regulator of eukaryotic cell growth. BMC Plant Biol. 5:2. doi: 10.1186/1471-2229-5-2

Anderson, P., and Kedersha, N. (2008). Stress granules: the Tao of RNA triage. Trends Biochem. Sci. 33, 141-150. doi: 10.1016/j.tibs.2007.12.003

Anderson, P., and Kedersha, N. (2009). RNA granules: post-transcriptional and epigenetic modulators of gene expression. Nat. Rev. Mol. Cell Biol. 10, 430-436. doi: $10.1038 / \mathrm{nrm} 2694$

Arimoto-Matsuzaki, K., Saito, H., and Takekawa, M. (2016). TIA1 oxidation inhibits stress granule assembly and sensitizes cells to stress-induced apoptosis. Nat. Commun. 7:10252. doi: 10.1038/ncomms10252

Arimoto, K., Fukuda, H., Imajoh-Ohmi, S., Saito, H., and Takekawa, M. (2008). Formation of stress granules inhibits apoptosis by suppressing stressresponsive MAPK pathways. Nat. Cell Biol. 10, 1324-1332. doi: 10.1038/ ncb1791

Arribas-Hernández, L., Kielpinski, L. J., and Brodersen, P. (2016). mRNA decay of most Arabidopsis miRNA targets requires slicer activity of AGO1. Plant Physiol. 171, 2620-2632. doi: 10.1104/pp.16.00231

Bai, Y., Falk, S., Schnittger, A., Jakoby, M. J., and Hulskamp, M. (2010). Tissue layer specific regulation of leaf length and width in Arabidopsis as revealed

\section{AUTHOR CONTRIBUTIONS}

HB designed, planned and performed the experiments, analyzed the data and wrote the manuscript. MH supervised the project and wrote the manuscript.

\section{FUNDING}

HB was funded by an IGSDHD fellowship.

\section{ACKNOWLEDGMENTS}

We are thankful to CECAD proteomics facility for performing the mass spectrometry analysis. We are thankful to Prof. Julia Bailey-Serres (University of California, Riverside) for providing us the 35S:PAB2-RFP lines. We thank Dr. Alexandra Steffens and Dr. Marc Jakoby for providing several cDNA clones used in this study. We thank Britta Müller for the technical assistance. We thank Dr. Swen Schellmann, Dr. Mark Jakoby and Lisa Stephan for critically reading the manuscript and for their suggestions.

\section{SUPPLEMENTARY MATERIAL}

The Supplementary Material for this article can be found online at: http://journal.frontiersin.org/article/10.3389/fpls.2017.01004/ full\#supplementary-material

by the cell autonomous action of ANGUSTIFOLIA. Plant J. 61, 191-199. doi: 10.1111/j.1365-313X.2009.04050.x

Bai, Y., Vaddepalli, P., Fulton, L., Bhasin, H., Hulskamp, M., and Schneitz, K. (2013). ANGUSTIFOLIA is a central component of tissue morphogenesis mediated by the atypical receptor-like kinase STRUBBELIG. BMC Plant Biol. 13:16. doi: 10.1186/1471-2229-13-16

Bailey-Serres, J., Sorenson, R., and Juntawong, P. (2009). Getting the message across: cytoplasmic ribonucleoprotein complexes. Trends Plant Sci. 14, 443453. doi: 10.1016/j.tplants.2009.05.004

Balasubramanian, P., Zhao, L. J., and Chinnadurai, G. (2003). Nicotinamide adenine dinucleotide stimulates oligomerization, interaction with adenovirus E1A and an intrinsic dehydrogenase activity of CtBP. FEBS Lett. 537, 157-160. doi: 10.1016/S0014-5793(03)00119-4

Barrios-Rodiles, M., Brown, K. R., Ozdamar, B., Bose, R., Liu, Z., Donovan, R. S., et al. (2005). High-throughput mapping of a dynamic signaling netowrk in mammalian cells. Science 307, 1621-1625. doi: 10.1126/science.1105776

Borgal, L., Rinschen, M. M., Dafinger, C., Hoff, S., Reinert, M. J., Lamkemeyer, T., et al. (2014). Casein Kinase $1 \propto$ phosphorylates the Wnt regulator jade- 1 and modulates its activity. J. Biol. Chem. 289, 26344-26356. doi: 10.1074/jbc.M114. 562165

Buchan, J. R., and Parker, R. (2009). Eukaryotic stress granules: the ins and outs of translation. Mol. Cell. 36, 932-941. doi: 10.1016/j.molcel.2009.11.020

Candé, C., Vahsen, N., Métivier, D., Tourrière, H., Chebli, K., Garrido, C., et al. (2004). Regulation of cytoplasmic stress granules by apoptosis-inducing factor. J. Cell Sci. 117, 4461-4468. doi: 10.1242/jcs.01356

Carbonell, A., Fahlgren, N., Garcia-Ruiz, H., Gilbert, K. B., Montgomery, T. A., Nguyen, T., et al. (2012). Functional analysis of three Arabidopsis ARGONAUTES using slicer-defective mutants. Plant Cell 24, 3613-3629. doi: $10.1105 /$ tpc. 112.099945

Carpio, Marcos, A., López Sambrooks, C., Durand, E. S., and Hallak, M. E. (2010). The arginylation-dependent association of calreticulin with stress granules is regulated by calcium. Biochem. J. 429, 63-72. doi: 10.1042/bj20091953 
Chinnadurai, G. (2002). CtBP, an unconventional transcriptional corepressor in development and oncogenesis. Mol. Cell 9, 213-224. doi: 10.1016/S10972765(02)00443-4

Chinnadurai, G. (2007). Transcriptional regulation by C-terminal binding proteins. Int. J. Biochem. Cell Biol. 39, 1593-1607. doi: 10.1016/j.biocel.2007. 01.025

Cho, K. H., Shindo, T., Kim, G. T., Nitasaka, E., and Tsukaya, H. (2005). Characterization of a member of the AN subfamily, IAN, from Ipomoea nil. Plant Cell Physiol. 46, 250-255. doi: 10.1093/pcp/pci020

Ciuzan, O., Hancock, J., Pamfil, D., Wilson, I., and Ladomery, M. (2015). The evolutionarily conserved multifunctional glycine-rich RNA-binding proteins play key roles in development and stress adaptation. Physiol. Plant. 153, 1-11. doi: $10.1111 / \mathrm{ppl} .12286$

Clough, S. J., and Bent, A. F. (1998). Floral dip: a simplified method for Agrobacterium-mediated transformation of Arabidopsis thaliana. Plant J. 16, 735-743. doi: 10.1046/j.1365-313x.1998.00343.x

Colanzi, A., Grimaldi, G., Catara, G., Valente, C., Cericola, C., Liberali, P., et al. (2013). Molecular mechanism and functional role of brefeldin A-mediated ADP-ribosylation of CtBP1/BARS. Proc. Natl. Acad. Sci. U.S.A. 110, 9794-9799. doi: 10.1073/pnas.1222413110

Dreyfuss, G., Kim, V. N., and Kataoka, N. (2002). Messenger-RNA-binding proteins and the messages they carry. Nat. Rev. Mol. Cell Biol. 3, 195-205. doi: $10.1038 / \mathrm{nrm} 760$

Dunn, K. W., Kamocka, M. M., and McDonald, J. H. (2011). A practical guide to evaluating colocalization in biological microscopy. Am. J. Physiol. Cell Physiol. 300, C723-C742. doi: 10.1152/ajpcell.00462.2010

Feys, B. J., Wiermer, M., Bhat, R. A., Moisan, L. J., Medina-Escobar, N., Neu, C., et al. (2005). Arabidopsis SENESCENCE-ASSOCIATED GENE101 stabilizes and signals within an ENHANCED DISEASE SUSCEPTIBILITY1 complex in plant innate immunity. Plant Cell 17, 2601-2613. doi: 10.1105/tpc.105.033910

Fjeld, C. C., Birdsong, W. T., and Goodman, R. H. (2003). Differential binding of NAD + and NADH allows the transcriptional corepressor carboxyl-terminal binding protein to serve as a metabolic sensor. Proc. Natl. Acad. Sci. U.S.A. 100, 9202-9207. doi: 10.1073/pnas.1633591100

Folkers, U., Kirik, V., Schobinger, U., Falk, S., Krishnakumar, S., Pollock, M. A., et al. (2002). The cell morphogenesis gene ANGUSTIFOLIA encodes a CtBP/BARS-like protein and is involved in the control of the microtubule cytoskeleton. EMBO J. 21, 1280-1288. doi: 10.1093/emboj/21.6.1280

Fulton, L., Batoux, M., Vaddepalli, P., Yadav, R. K., Busch, W., Andersen, S. U., et al. (2009). DETORQUEO, QUIRKY, and ZERZAUST represent novel components involved in organ development mediated by the receptorlike kinase STRUBBELIG in Arabidopsis thaliana. PLoS Genet. 5:e1000355. doi: 10.1371/journal.pgen.1000355

Gachomo, E. W., Jimenez-Lopez, J. C., Smith, S. R., Cooksey, A. B., Oghoghomeh, O. M., Johnson, N., et al. (2013). The cell morphogenesis ANGUSTIFOLIA (AN) gene, a plant homolog of CtBP/BARS, is involved in abiotic and biotic stress response in higher plants. BMC Plant Biol. 13:79. doi: 10.1186/1471-222913-79

Gietz, R. D., Schiestl, R. H., Willems, A. R., and Woods, R. A. (1995). Studies on the transformation of intact yeast cells by the LiAc/SS-DNA/PEG procedure. Yeast 11, 355-360. doi: 10.1002/yea.320110408

Gutierrez-Beltran, E., Moschou, P. N., Smertenko, A. P., and Bozhkov, P. V. (2015). Tudor staphylococcal nuclease links formation of stress granules and processing bodies with mRNA catabolism in Arabidopsis. Plant Cell 27, 926-943. doi: 10.1105/tpc.114.134494

Hafrén, A., Lõhmus, A., and Mäkinen, K. (2015). Formation of potato virus A-induced RNA granules and viral translation are interrelated processes required for optimal virus accumulation. PLoS Pathog. 11:e1005314. doi: 10.1371/journal.ppat.1005314

Hossain, M. A., Bhattacharjee, S., Armin, S. M., Qian, P., Xin, W., Li, H. Y., et al. (2015). Hydrogen peroxide priming modulates abiotic oxidative stress tolerance: insights from ROS detoxification and scavenging. Front. Plant Sci. 6:420. doi: 10.3389/fpls.2015.00420

Hosseinibarkooie, S., Peters, M., Torres-Benito, L., Rastetter, R. H., Hupperich, K., Hoffmann, A., et al. (2016). The power of human protective modifiers: PLS3 and CORO1C unravel impaired endocytosis in spinal muscular atrophy and rescue SMA phenotype. Am. J. Hum. Genet. 99, 647-665. doi: 10.1016/j.ajhg.2016. 07.014
Hulskamp, M., Misera, S., and Jürgens, G. (1994). Genetic dissection of trichome cell development in Arabidopsis. Cell 76, 555-566. doi: 10.1016/0092-8674(94) 90118-X

Kaur, J., Sebastian, J., and Siddiqi, I. (2006). The Arabidopsis-mei2-like genes play a role in meiosis and vegetative growth in Arabidopsis. Plant Cell 18, 545-559. doi: $10.1105 /$ tpc. 105.039156

Kawaguchi, R., and Bailey-Serres, J. (2002). Regulation of translational initiation in plants. Curr. Opin. Plant Biol. 5, 460-465. doi: 10.1016/S1369-5266(02)00290-X

Kedersha, N., Chen, S., Gilks, N., Li, W., Miller, I. J., Stahl, J., et al. (2002). Evidence that ternary complex (eIF2-GTP-tRNAi Met)-deficient preinitiation complexes are core constituents of Mammalian Stress Granules. Mol. Biol. Cell 13, 195-210. doi: 10.1091/mbc.01-05-0221

Kedersha, N., Ivanov, P., and Anderson, P. (2013). Stress granules and cell signaling: more than just a passing phase? Trends Biochem. Sci. 38, 494-506. doi: 10.1016/j.tibs.2013.07.004

Kedersha, N., Stoecklin, G., Ayodele, M., Yacono, P., Lykke-Andersen, J., Fritzler, M. J., et al. (2005). Stress granules and processing bodies are dynamically linked sites of mRNP remodeling. J. Cell Biol. 169, 871-884. doi: 10.1083/jcb. 200502088

Kim, G. T., Shoda, K., Tsuge, T., Cho, K. H., Uchimiya, H., Yokoyama, R., et al. (2002). The ANGUSTIFOLIA gene of Arabidopsis, a plant CtBP gene, regulates leaf-cell expansion, the arrangement of cortical microtubules in leaf cells and expression of a gene involved in cell-wall formation. EMBO J. 21, 1267-1279. doi: 10.1093/emboj/21.6.1267

Kim, W.-C., Kim, J.-Y., Ko, J.-H., Kang, H., Kim, J., and Han, K.-H. (2014). AtC3H14, a plant-specific tandem $\mathrm{CCCH}$ zinc-finger protein, binds to its target mRNAs in a sequence-specific manner and affects cell elongation in Arabidopsis thaliana. Plant J. 80, 772-784. doi: 10.1111/tpj.12667

Kimball, S. R., Horetsky, R. L., Ron, D., Jefferson, L. S., and Harding, H. P. (2003). Mammalian stress granules represent sites of accumulation of stalled translation initiation complexes. Am. J. Physiol. Cell Physiol. 284, C273. doi: 10.1152/ajpcell. 00314.2002

Kuppuswamy, M., Vijayalingam, S., Zhao, L. J., Zhou, Y., Subramanian, T., Ryerse, J., et al. (2008). Role of the PLDLS-binding cleft region of CtBP1 in recruitment of core and auxiliary components of the corepressor complex. Mol. Cell. Biol. 28, 269-281. doi: 10.1128/MCB.01077-7

Lee, S.-J., Jung, H. J., Kang, H., and Kim, S. Y. (2012). Arabidopsis Zinc Finger Proteins AtC3H49/AtTZF3 and AtC3H20/AtTZF2 are Involved in ABA and JA Responses. Plant Cell Physiol. 53, 673-686. doi: 10.1093/pcp/pcs023

Lin, X., Minamisawa, N., Takechi, K., Zhang, W., Sato, H., Takio, S., et al. (2008). Isolation and characterization of the Larix gmelinii ANGUSTIFOLIA (LgAN) gene. Planta 228, 601-608. doi: 10.1007/s00425-008-0762-9

Lokdarshi, A., Conner, W. C., McClintock, C., Li, T., and Roberts, D. (2016). Arabidopsis CML38, a calcium sensor that localizes to ribonucleoprotein complexes under hypoxia stress. Plant Physiol. 170, 1046-1059. doi: 10.1104/ pp. 15.01407

Lorkovic, Z. J. (2009). Role of plant RNA-binding proteins in development, stress response and genome organization. Trends Plant Sci. 14, 229-236. doi: 10.1016/ j.tplants.2009.01.007

Lorković, Z. J., and Barta, A. (2002). Genome analysis: RNA recognition motif (RRM) and $\mathrm{K}$ homology $(\mathrm{KH})$ domain RNA-binding proteins from the flowering plant Arabidopsis thaliana. Nucleic Acids Res. 30, 623-635. doi: 10.1093/nar/30.3.623

Lorkovic, Z. J., Wieczorek Kirk, D. A., Klahre, U., Hemmings-Mieszczak, M., and Filipowicz, W. (2000). RBP45 and RBP47, two oligouridylate-specific hnRNPlike proteins interacting with poly(A)+ RNA in nuclei of plant cells. RNA 6, 1610-1624. doi: 10.1017/S1355838200001163

Madison, D. L., Wirz, J. A., Seiss, D., and Lundblad, J. R. (2013). Nicotinamide adenine dinucleotide induced multimerization of the co-repressor CtBP1 relies on a switching tryptophan. J. Biol. Chem. 288, 27836-27848. doi: 10.1074/jbc. M113.493569

Mangeon, A., Junqueira, R. M., and Sachetto-Martins, G. (2010). Functional diversity of the plant glycine-rich proteins superfamily. Plant Signal. Behav. 5, 99-104. doi: 10.4161/psb.5.2.10336

Mathur, J., Mathur, N., Kirik, V., Kernebeck, B., Srinivas, B. P., and Hülskamp, M. (2003). $<$ em $>$ Arabidopsis CROOKED $</$ em $>$ encodes for the smallest subunit of the ARP2/3 complex and controls cell shape by region specific fine F-actin formation. Development 130, 3137-3146. doi: 10.1242/dev.00549 
McCue, A. D., Nuthikattu, S., Reeder, S. H., and Slotkin, R. K. (2012). Gene expression and stress response mediated by the epigenetic regulation of a transposable element small RNA. PLOS Genet. 8:e1002474. doi: 10.1371/ journal.pgen.1002474

Minamisawa, N., Sato, M., Cho, K. H., Ueno, H., Takechi, K., Kajikawa, M., et al. (2011). ANGUSTIFOLIA, a plant homolog of CtBP/BARS, functions outside the nucleus. Plant J. 68, 788-799. doi: 10.1111/j.1365-313X.2011.04731.x

Nakaminami, K., Hill, K., Perry, S. E., Sentoku, N., Long, J. A., and Karlson, D. T. (2009). Arabidopsis cold shock domain proteins: relationships to floral and silique development. J. Exp. Bot. 60, 1047-1062. doi: 10.1093/jxb/ern351

Nardini, M., Valente, C., Ricagno, S., Luini, A., Corda, D., and Bolognesi, M. (2009). CtBP1/BARS Gly172- > Glu mutant structure: impairing NAD(H)binding and dimerization. Biochem. Biophys. Res. Commun. 381, 70-74. doi: 10.1016/j.bbrc.2009.02.010

Pesch, M., Dartan, B., Birkenbihl, R., Somssich, I. E., and Hülskamp, M. (2014). Arabidopsis TTG2 regulates TRY expression through enhancement of activator complex-triggered activation. Plant Cell 26, 4067-4083. doi: 10.1105/tpc.114. 129379

Pesch, M., Schultheiß, I., Digiuni, S., Uhrig, J. F., and Hülskamp, M. (2013). Mutual control of intracellular localisation of the patterning proteins AtMYC1, GL1 and TRY/CPC in Arabidopsis. Development 140, 3456. doi: 10.1242/dev.094698

Pesch, M., Schultheiß, I., Klopffleisch, K., Uhrig, J. F., Koegl, M., Clemen, C. S., et al. (2015). TRANSPARENT TESTA GLABRA1 and GLABRA1 compete for binding to GLABRA3 in Arabidopsis. Plant Physiol. 168, 584-597. doi: 10.1104/ pp. 15.00328

Pomeranz, M. C., Hah, C., Lin, P. C., Kang, S. G., Finer, J. J., Blackshear, P. J., et al. (2010). The Arabidopsis tandem zinc finger protein AtTZF1 traffics between the nucleus and cytoplasmic foci and binds both DNA and RNA. Plant Physiol. 152, 151-165. doi: 10.1104/pp.109.145656

Redei, G. P. (1962). Single locus heterosis. Z. Vererbungsl. 93, 164-170.

Rinnerthaler, M., Lejskova, R., Grousl, T., Stradalova, V., Heeren, G., Richter, K., et al. (2013). Mmil, the yeast homologue of mammalian TCTP, associates with stress granules in heat-shocked cells and modulates proteasome activity. PLoS ONE 8:e77791. doi: 10.1371/journal.pone.0077791

Ruhl, C., Stauffer, E., Kahles, A., Wagner, G., Drechsel, G., Ratsch, G., et al. (2012). Polypyrimidine tract binding protein homologs from Arabidopsis are key regulators of alternative splicing with implications in fundamental developmental processes. Plant Cell 24, 4360-4375. doi: 10.1105/tpc.112.103622

Sambade, A., Findlay, K., Schaffner, A. R., Lloyd, C. W., and Buschmann, H. (2014). Actin-dependent and -independent functions of cortical microtubules in the differentiation of Arabidopsis leaf trichomes. Plant Cell 26, 1629-1644. doi: $10.1105 /$ tpc.113.118273

Sasaki, K., Kim, M. H., and Imai, R. (2007). Arabidopsis COLD SHOCK DOMAIN PROTEIN2 is a RNA chaperone that is regulated by cold and developmental signals. Biochem. Biophys. Res. Commun. 364, 633-638. doi: 10.1016/j.bbrc. 2007.10.059

Schaeper, U., Boyd, J. M., Verma, S., Uhlmann, E., Subramanian, T., and Chinnadurai, G. (1995). Molecular cloning and characterization of a cellular phosphoprotein that interacts with a conserved C-terminal domain of adenovirus E1A involved in negative modulation of oncogenic transformation. Proc. Natl. Acad. Sci. U.S.A. 92, 10467-10471. doi: 10.1073/pnas.92.23.10467

Schmidt, F., Marnef, A., Cheung, M. K., Wilson, I., Hancock, J., Staiger, D., et al. (2010). A proteomic analysis of oligo(dT)-bound mRNP containing oxidative stress-induced Arabidopsis thaliana RNA-binding proteins ATGRP7 and ATGRP8. Mol. Biol. Rep. 37, 839-845. doi: 10.1007/s11033009-9636-X

Somasekharan, S. P., El-Naggar, A., Leprivier, G., Cheng, H., Hajee, S., Grunewald, T. G., et al. (2015). YB-1 regulates stress granule formation and tumor progression by translationally activating G3BP1. J. Cell Biol. 208, 913-929. doi: $10.1083 /$ jcb.201411047

Sorenson, R., and Bailey-Serres, J. (2014). Selective mRNA sequestration by OLIGOURIDYLATE-BINDING PROTEIN 1 contributes to translational control during hypoxia in Arabidopsis. Proc. Natl. Acad. Sci. U.S.A. 111, 2373-2378. doi: 10.1073/pnas.1314851111

Spano, S., Silletta, M. G., Colanzi, A., Alberti, S., Fiucci, G., Valente, C., et al. (1999). Molecular cloning and functional characterization of brefeldin A-ADPribosylated substrate. A novel protein involved in the maintenance of the Golgi structure. J. Biol. Chem. 274, 17705-17710. doi: 10.1074/jbc.274.25. 17705

Stauffer, E., Westermann, A., Wagner, G., and Wachter, A. (2010). Polypyrimidine tract-binding protein homologues from Arabidopsis underlie regulatory circuits based on alternative splicing and downstream control. Plant J. 64, 243-255. doi: 10.1111/j.1365-313X.2010.04321.x

Stern, M. D., Aihara, H., Cho, K. H., Kim, G. T., Horiguchi, G., Roccaro, G. A., et al. (2007). Structurally related Arabidopsis ANGUSTIFOLIA is functionally distinct from the transcriptional corepressor CtBP. Dev. Genes Evol. 217, 759-769. doi: 10.1007/s00427-007-0186-8

Tsuge, T., Tsukaya, H., and Uchimiya, H. (1996). Two independent and polarized processes of cell elongation regulate leaf blade expansion in Arabidopsis thaliana. Development 122, 1589-1600.

Tsukaya, H., Tsuge, T., and Uchimiya, H. (1994). The cotyledon: a superior system for studies of leaf development. Planta 195, 309-312. doi: 10.1007/BF00199692

Walters, R. W., Shumilin, I. A., Yoon, J. H., Minor, W., and Parker, R. (2014). Edc3 function in yeast and mammals is modulated by interaction with NAD-related compounds. G3 4, 613-622. doi: 10.1534/g3.114.010470

Weber, C., Nover, L., and Fauth, M. (2008). Plant stress granules and mRNA processing bodies are distinct from heat stress granules. Plant J. 56, 517-530. doi: 10.1111/j.1365-313X.2008.03623.x

Wippich, F., Bodenmiller, B., Trajkovska, M. G., Wanka, S., Aebersold, R., and Pelkmans, L. (2013). Dual specificity kinase DYRK3 couples stress granule condensation/dissolution to mTORC1 signaling. Cell 152, 791-805. doi: 10.1016/j.cell.2013.01.033

$\mathrm{Xu}$, J., and Chua, N.-H. (2009). Arabidopsis decapping 5 is required for mRNA decapping, P-body formation, and translational repression during postembryonic development. Plant Cell 21, 3270-3279. doi: 10.1105/tpc.109. 070078

Xu, J., Yang, J. Y., Niu, Q. W., and Chua, N. H. (2006). Arabidopsis DCP2, DCP1, and VARICOSE form a decapping complex required for postembryonic development. Plant Cell 18, 3386-3398. doi: 10.1105/tpc.106.047605

Yuan, H. X., Xiong, Y., and Guan, K. L. (2013). Nutrient sensing, metabolism, and cell growth control. Mol. Cell. 49, 379-387. doi: 10.1016/j.molcel.2013. 01.019

Zhang, Q., Piston, D. W., and Goodman, R. H. (2002). Regulation of corepressor function by nuclear NADH. Science 295, 1895-1897. doi: 10.1126/science. 1069300

Zhang, Y. W., and Arnosti, D. N. (2011). Conserved catalytic and C-terminal regulatory domains of the $\mathrm{C}$-terminal binding protein corepressor fine-tune the transcriptional response in development. Mol. Cell Biol. 31, 375-384. doi: 10.1128/MCB.00772-10

Conflict of Interest Statement: The authors declare that the research was conducted in the absence of any commercial or financial relationships that could be construed as a potential conflict of interest.

The reviewer $\mathrm{TH}$ and handling Editor declared their shared affiliation, and the handling Editor states that the process met the standards of a fair and objective review.

Copyright (C) 2017 Bhasin and Hülskamp. This is an open-access article distributed under the terms of the Creative Commons Attribution License (CC BY). The use, distribution or reproduction in other forums is permitted, provided the original author(s) or licensor are credited and that the original publication in this journal is cited, in accordance with accepted academic practice. No use, distribution or reproduction is permitted which does not comply with these terms. 